Original Research Paper - Journal of Composite Materials

Corresponding author:

Mael Péron, Université de Nantes, 58 Rue Michel Ange, Saint Nazaire, France

Email: mael.peron@univ-nantes.fr

\title{
THERMOMECHANICAL CHARACTERIZATION OF A LOW VISCOSITY PA66 THERMOPLASTIC MATRIX AND ASSOCIATED CONTINUOUS GLASS FIBER COMPOSITE UNDER PROCESSING CONDITIONS
}

\author{
Mael Péron ${ }^{1,2}$, Frédéric Jacquemin ${ }^{1}$, Pascal Casari ${ }^{1}$, Gilles Orange ${ }^{3}$, \\ Jean-Luc Bailleul ${ }^{4}$, Nicolas Boyard ${ }^{4}$ \\ ${ }^{1}$ Institut de Recherche en Génie Civil et Mécanique (GeM) - UMR CNRS 6183 \\ 58 Rue Michel Ange, 44600 Saint Nazaire, France \\ ${ }^{2}$ IRT Jules Verne
}

Chemin du Chaffault, 44340 Bouguenais, France

${ }^{3}$ RICLSolvay

87 Avenue des Frères Perret, CS 70061, 69192 Saint Fons, France

${ }^{4}$ Laboratoire de Thermique et Energie de Nantes (LTEN) - UMR CNRS 6607

Rue Christian Pauc, CS 50609, 44306 Nantes CEDEX 3, France

\begin{abstract}
Characterizing the thermomechanical properties of thermoplastic resins and associated composites is of outmost importance to understand the development of process induced stresses. To that extent, the characterization of a low viscosity PA66 matrix is proposed thanks to a homemade volumetric dilatometer named PvT-XT and a Dynamic Mechanical Analyser (DMA) on a wide temperature range. The PvT-XT results, reported for the first time, permit to identify the evolution of the coefficients of thermal expansion (CTE), of crystallization shrinkage and of the bulk modulus with temperature. DMA experiments leads to the estimation of the Young's modulus. The shear modulus as well as the Poisson's ratio are then estimated thanks to analytical relations for isotropic and homogeneous materials. These properties are used to feed a new analytical model estimating the CTE of quasi-unidirectional composites. All the results are compared with values from the literature or from complementary experiments, showing a good agreement which permits to validate the developed methodology.
\end{abstract}

Keywords

Thermoplastic resin, glass fibres, thermomechanical, mechanical testing, composites 


\section{Introduction}

Since the early 2000s, the automotive industry faces drastic objectives in terms of $\mathrm{CO}_{2}$ emission reduction. For example, the European Commission together with the European Road Transport Research Advisory Council aim at a reduction of $40 \%$ of the $\mathrm{CO}_{2}$ emission by 2021. In order to face these approaching goals, car manufacturers had to recently improve the lightness of their vehicles. This sector has therefore developed a recent interest in thermoplastic composites as a substitute to metallic alloys. Among them, continuous glass fiber reinforced polyamide 66 (PA66) composites seem of particular interest due to their numerous advantages, such as its ease of forming and favorable mechanical properties [1-3]. However, the polyamide 66 high viscosity makes it difficult to use this polymer in composite injection processes as Resin Transfer Molding (RTM), especially in presence of important fiber content (i.e. $>50 \%$ vol). Also, in order to face the high production rate met in the automotive sector, cooling of the thermoplastic parts must be performed as quickly as possible. This might alter the final part health, leading to heterogeneous properties through the thickness of the part and residual stresses [4,5].

In this context, the TAPAS project (ThermoplAstic Process for Automotive Structure, ANR-11-RMNP-0020) aimed at developing a low viscosity PA66 polymer and the associated RTM process in order to produce continuous glass fiber reinforced PA66 composite plates. A PA66 matrix was developed at lab scale, permitting to attain a $15 \mathrm{~Pa} . \mathrm{s}$ viscosity at $280^{\circ} \mathrm{C}$ at low shear rate. The impregnation of the fibers was also enhanced through the development of an improved reinforcement architecture. The quality of the impregnation and reduction of the filling time were controlled, which permitted to validate the RTM process parameters [6]. Even though the final part quality highly relies on the impregnation step of the process, heat transfer and thermomechanical behavior of the material during cooling also play a critical role to achieve a part with good properties. Through their different studies [7-9], Faraj et al. were able to precisely describe the heat transfer and crystallization kinetics of the freshly developed composite. The evaluation of the thermomechanical behavior of the developed material was still to investigate.

During cooling, thermoplastic composites are inevitably submitted to the development of residual stresses [4], which are partly due to the mismatch of thermomechanical behavior between the fibers and the matrix. These stresses might have significant severe impact on the final part health, including microcracking, shape distortion and lower mechanical properties [5]. To understand the development of such stresses during manufacturing, it appears as essential to characterize the evolution of the matrix and composite thermomechanical properties. Once described, this behavior can feed predictive models to evaluate the development of residual stresses and strains during cooling [10]. This represents considerable cost and time saving compared to trial and error methods. Numerous models have been explored and are presented in [10]. In the following, focus will be made on linear elastic models, neglecting the viscoelastic behavior of the material. For semi-crystalline matrix composites, these stresses start to develop below the crystallization temperature [4]. Therefore, it is of primary importance to identify their properties from crystallization temperature to room temperature. 
Among the different properties commonly used to predict the thermomechanical behavior of the thermoplastic matrix during cooling, one can find the elastic moduli such as the Young's modulus $E_{m}$, the shear modulus $G_{m}$ or the bulk modulus $K_{m}$, the Poisson's coefficient $v_{m}$, and the coefficients of volumetric thermal expansion $\alpha_{V m}$ and of volumetric crystallization shrinkage $\beta_{V m}$. Numerous methods can be found to determine these properties and their evolutions with temperature from the melt stage (i.e. around $260^{\circ} \mathrm{C}$ ) to room temperature $\left(25^{\circ} \mathrm{C}\right)$. The PA66 Young's modulus has been characterized thanks to acoustic waves transducers [11,12], visco-elastometer [13], dynamic tensile tests [14,15] and DMA [16]. Fewer references can be found concerning its shear modulus evolution with temperature, and only the use of torsion pendulum is reported [14,17-20]. Only a couple of studies reference the evaluation of the PA66 bulk modulus as a function of temperature. They include the use of high pressure volumetric dilatometers [21,22] or the use of sound transducers [23]. These studies are however limited to a temperature range in the semicrystalline state of the matrix, from 0 to $200^{\circ} \mathrm{C}$. The measurement of the Poisson's ratio evolution with temperature has rarely been mentioned in previous studies, and this property is often calculated thanks to the aforementioned moduli. The coefficient of thermal expansion of PA66 have already been studied thanks to a mercury column dilatometer [24], a linear dilatometer [25,26] or Thermal Mechanical Analysis (TMA) [27]. The first method permits to follow the volume evolution of the sample from melting to room temperature. However as it contains mercury it is not allowed to be used in Europe anymore nowadays. The two other methods are on another hand not adapted to high temperatures (i.e. above the glass transition temperature of the matrix $T_{g} \approx 60^{\circ} \mathrm{C}$ ), as the mechanical loading might lead the matrix to creep. The other way to obtain the evolution of the coefficient of thermal expansion as well as of crystallization shrinkage relies in the use of plunger type volumetric dilatometer $[28,29]$ to measure the evolution of the specific volume of the matrix during cooling. During this phase, crystallization shrinkage happens together with thermal contraction of the matrix. Therefore, crystallization and thermal contributions to the global volume evolution have to be uncorrelated in order to determine the associated coefficients. Several limitations appear from the different studies related to the characterization of the PA66 thermomechanical properties evolution with temperature. First of all, it often requires the use of at least three different devices in order to obtain all the needed properties e.g. a DMA, a linear or volumetric dilatometer and a torsion pendulum. This leads to time consuming methodology and the investment in (or development of) specific devices. Secondly, the PA66 bulk modulus evolution over a wide range of temperature has never been reported in the literature. Finally, uncorrelating crystallization and thermal contribution to the overall volume evolution of the PA66 is necessary in order to identify its thermal expansion and crystallization shrinkage coefficients.

Composite plates with important in-plane dimensions compared to their thickness were produced within the TAPAS project. The most important composite properties governing the thermomechanical of the part during cooling are therefore the in-plane ones, i.e. in plane Young's moduli $E_{L}$ and $E_{T}$, shear modulus $G_{L T}$, Poisson's coefficient $v_{L T}$, and the in plane coefficients of thermal expansion $\alpha_{L}$ and $\alpha_{T}$, and of crystallization shrinkage $\beta_{L}$ and $\beta_{T}$. Several characterization have been adopted to measure these properties over a large range of temperatures, including tensile tests [30], DMA [28,31,32], TMA [33,34] or strain gages [30]. It has to be noted that these characterization techniques still represent a challenge in the study of the thermomechanical behavior of thermoplastic composites, as 
the material highly softens at elevated temperatures. Some improvements of the measurement devices are still necessary to achieve this goal, but will not be discussed here. Another way of providing these properties relies in the use of homogenization estimation methods, based on the properties of the constituents (i.e. the fibers and the matrix) and on the microstructure of the material. Numerous models can be found in the literature to estimate these effective properties in the case of unidirectional (UD) or woven composites [35]. The ease of implementation of these methods highly depend on the accuracy of the description of the material architecture. Among them, one can find estimations via energetic bounds [36], use of the laminate theory [35] and finite element calculations [37]. However, no simple analytical model could be found to estimate the properties of quasiunidirectional (QUD) thermoplastic based composite materials.

To face these limitations, the authors propose a complete characterization of the PA66 and its thermomechanical properties evolution with temperature with only two devices. A DMA is used to obtain the Young's modulus of the matrix as a function of the temperature. Then, a plunger-type dilatometer called PvT-XT [29] permits the measurement of the specific volume of PA66 samples on a large range of temperature and for several pressure levels (from 20 to $40 \mathrm{MPa}$ ). From these results, the coefficient of thermal expansion and of crystallization shrinkage are estimated, as well as the bulk modulus of PA66. These properties then feed a simple estimation model of a quasiunidirectional long fiber glass reinforced composite, leading to the different properties needed to model the in-plane behavior of the material. These properties are finally compared with experimentally obtained ones, so as to validate the developed model.

\section{Materials and methods}

\section{Materials}

The material studied in the present work comes from recent developments and research concerning low-viscosity thermoplastic matrix and is part of the TAPAS research program [6,7]. The composite material on which this study relies is thus composed of a specifically developed polyamide 66 matrix (Solvay) and quasi-unidirectional glass fiber reinforcement (Chomarat). The reinforcement architecture (Fig. 1) is composed of principal yarns in the warp direction, spacer yarns in the warp direction to create matrix flow channels between each principal yarns, and of secondary yarns in the weft direction. The warp yarns, spacers and weft yarns represent approximately 85, 10 and 5\% of the total fiber volume, respectively.

Five samples of neat matrix of dimensions $50 \times 10 \times 5 \mathrm{~mm}^{3}$ were manufactured by injection molding. In addition, different composite plates were studied with two lay-up sequences: $[0]_{8}$ and $\left[\begin{array}{ll}90_{2} & 02\end{array}\right]$ s. For each ply sequence, one plate of in-plane dimensions $500 \times 500 \mathrm{~mm}^{2}$ and a targeted $50 \%$ vol of fibers was manufactured by thermoforming by Solvay. The $[0]_{8}$ plate was then cut into samples of in-plane dimensions $50 \times 10 \mathrm{~mm}^{2}$, leading to 5 samples of $[0]_{8}$ and 10 samples of [90]8 ply sequence. The $\left[90_{2} 0_{2}\right]_{s}$ plate was cut into 3 samples of $200 \times 30 \mathrm{~mm}^{2}$ along its $45^{\circ}$ directions, thus leading to three samples of [ $+45_{2}$ $-45_{2}$ ]s ply sequences. For the different following characterization techniques, all the 
samples were dried under a $-0.09 \mathrm{MPa}$ vacuum at $90^{\circ} \mathrm{C}$ during at least 10 hours prior testing to ensure the samples are dry.

\section{Neat matrix characterization}

The neat matrix was first tested thanks to a Mettler Toledo DMA testing machine configured in 3 points bending. The samples were loaded under a $6 \mathrm{~N}$ preload to ensure a good contact of the sample with the device, and a $1 \mathrm{~Hz}$ frequency and $5 \mu \mathrm{m}$ amplitude displacement. They were heated from $-50^{\circ} \mathrm{C}$ to $150^{\circ} \mathrm{C}$ under a nitrogen flow at a rate of $2^{\circ} \mathrm{C} / \mathrm{min}$ to ensure thermal homogeneity of the samples. This led to the evolution of the matrix Young's modulus $E_{m}$ with temperature.

Neat matrix pellets were also characterized thanks to a PvT-XT volumetric dilatometer [7,29]. Approximately 10 grams of matrix pellets were put inside the dilatometer molding cavity and heated at $300^{\circ} \mathrm{C}$ under a prescribed pressure level for three minutes to ensure a total melting of the matrix. They were then cooled to $30^{\circ} \mathrm{C}$ at $2^{\circ} \mathrm{C} \cdot \mathrm{min}^{-}$

1 in order to limit the temperature and crystallization gradients in the samples. Three different pressure levels were investigated here, i.e. 20, 30 and $40 \mathrm{MPa}$. This led to the evolution of the specific volume of the matrix with temperature for several hydrostatic pressure levels. Treatment of these volume evolutions leads to the estimation of the coefficient of crystallization shrinkage, of the coefficient of thermal expansion and of the bulk modulus of the neat matrix. The methods and results are described in section 3.1.

\section{Composite characterization}

Tensile tests were performed on the [ $\left.+45_{2}-45_{2}\right]$ s samples at $25^{\circ} \mathrm{C}$ on a Zwick Roell Z050 tensile machine. Tests were performed following the ASTM D3039 standard, by imposing a $2 \mathrm{~mm} / \mathrm{min}$ displacement rate on the samples. These latter were instrumented with two strain gages along their longitudinal and transversal direction, and strains from $500 \mu \varepsilon$ to $1500 \mu \varepsilon$ were considered to identify the material behavior. As described in section 3.2, a plane stress model was used to identify the mechanical behavior of the samples. This led to an estimation of the in-plane shear modulus $G_{L T}$ at room temperature.

Then, ten composite samples extracted from the $[0]_{8}$ plate were tested thanks to the DMA device mounted in 3 points bending configuration. The samples, five of each $[0]_{8}$ and $[90]_{8}$ ply sequences, were loaded under a $7 \mathrm{~N}$ preload, a $1 \mathrm{~Hz}$ frequency and a $5 \mu \mathrm{m}$ amplitude displacement. They were heated from $25^{\circ} \mathrm{C}$ to $200^{\circ} \mathrm{C}$ and $120^{\circ} \mathrm{C}$ for the [0]8 and [90]8 ply sequences, respectively, at a heating rate of $2^{\circ} \mathrm{C} \cdot \mathrm{min}^{-1}$ to limit temperature gradients. The maximum temperature is lower in the case of the [90]8 ply sequence to ensure the samples do not creep during the tests. This permitted to estimate the longitudinal and transversal Young's modulus of the composite, $E_{L}$ and $E_{T}$, respectively, and their evolution with temperature. Finally, the five remaining samples of the [90]8 ply sequence were tested using a LINSEIS L75 PT linear dilatometer. The samples were submitted to a $100 \mathrm{mN}$ compressive load, and heated from room temperature to $150^{\circ} \mathrm{C}$ at a $2^{\circ} \mathrm{C} / \mathrm{min}$ heating rate to evaluate the composite coefficient of thermal expansion along its transversal direction $\alpha_{T}$. 


\section{Experimental characterization}

Two characterization methods were considered to obtain the thermo-mechanical properties of the composite material. The first one consists in the direct characterization of the matrix properties. From these properties, and assuming the fiber properties are known, it is possible to predict the composite equivalent properties thanks to homogenization methods. The second method consists in a direct characterization of the composite properties. The two approaches are developed in the following sections, and results from both routes are compared.

\section{Neat matrix characterization}

\section{DMA Characterization}

The three points bending tests from the DMA device led to an estimation of the storage modulus $E^{\prime}$ of the matrix and its evolution with temperature. The mean value of this modulus for the five tested samples is represented in Fig. 2. The error bars correspond to the composed measurement uncertainty, as depicted in the Guide to the expression of Uncertainty in Measurement (GUM) [38]. All the measurement uncertainties are expressed following this method. The modulus highly decreases with temperature, and exhibits a neat transition from 30 to $100^{\circ} \mathrm{C}$. This transition is accompanied with an increase in the loss $\operatorname{tangent} \tan \delta$ on the same temperature range, which translates a rise in the viscous behavior of the matrix compared to its purely elastic one. The peak value of the loss tangent is found around $63 \pm 1{ }^{\circ} \mathrm{C}$ and is considered as the glass transition temperature $T_{g}$ of the matrix. $T_{g}$ values were obtained from Differential Scanning Calorimetry (DSC) measurements by Faraj [7] and were identified between 60 and $70^{\circ} \mathrm{C}$. The storage modulus evolution is compared with several values coming from previous studies [14-16], showing an excellent agreement. The glass transition from these previous studies seems however to be reached at a slightly higher temperature range, which is explained by the difference in the polyamide 66 formulation. Due to the relatively small imposed displacement amplitude, the storage modulus will be considered as representative of the matrix Young's modulus $E_{m}$ in the following of the study.

The obtained evolution of the matrix Young's modulus $E_{m}$ is fitted thanks to a mathematical function (Eq. 1), leading to less than $1 \%$ error between the experimental results and the proposed function.

$$
\left\{\begin{array}{l}
E_{m}(T)=E_{0}-\Delta E \cdot f_{m}(T)-E_{1} \cdot g_{m}(T), \\
f_{m}(T)=\tanh \left(\left(T-T_{m 0}\right) *\left(a_{m}-b_{m} * \tanh \left(0.5 * T-T_{m 0}\right)\right)\right), \\
g_{m}(T)=\frac{T}{T_{m 1}+T * c_{m}},
\end{array}\right.
$$

where the different characteristic values are depicted in table 1 . These characteristic were chosen to best fit the experimental data and they do not represent specific values of the material properties. 
Table 1: Characteristic values for the evolution of the matrix Young's modulus.

\begin{tabular}{lll} 
Characteristic & Unit & Value \\
\hline $\mathrm{E}_{0}$ & $(\mathrm{GPa})$ & 2.09 \\
$\Delta \mathrm{E}$ & $(\mathrm{GPa})$ & 0.715 \\
$\mathrm{E}_{1}$ & $(\mathrm{GPa})$ & 1 \\
$\mathrm{a}_{\mathrm{m}}$ & & 0.7 \\
$\mathrm{~b}_{\mathrm{m}}$ & & 0.02 \\
$\mathrm{C}_{\mathrm{m}}$ & & 0.35 \\
$\mathrm{~T}_{\mathrm{m} 0}$ & $\left({ }^{\circ} \mathrm{C}\right)$ & 48 \\
$\mathrm{~T}_{\mathrm{m} 1}$ & $\left({ }^{\circ} \mathrm{C}\right)$ & 120 \\
\hline
\end{tabular}

\section{Specific volume characterization}

The evolution of the specific volume of the neat resin for several pressure levels as a function of temperature and obtained from the PvT-XT experiments is represented in Fig. 3. It consists in the ratio between its volume and its initial mass. The error bars are not represented in Fig. 3, as Pignon et al. [29] showed that PvT-XT measurements on polyetherteherketone (PEEK) and polypropylene (PP) matrixes led to less than $0.53 \%$ error on the measured specific volume from 5 different samples. Indeed, the obtained specific volume for both matrixes ranged from $8.910^{-4}$ to $7.610^{-4} \mathrm{~m}^{3} \cdot \mathrm{kg}^{-1}$ for the PEEK matrix and from $12.410^{-4}$ to $10.910^{-4} \mathrm{~m}^{3} \cdot \mathrm{kg}^{-1}$ for the PP one, while cooling from 400 to $25^{\circ} \mathrm{C}$ and from 250 to $25^{\circ} \mathrm{C}$ for the PEEK and the PP, respectively. As the order of magnitudes for the measured specific volume is identical over similar temperature variations, the uncertainty is considered as equivalent to the one obtained by Pignon et al. .

Regardless of the pressure, the specific volume decreases with the temperature on the whole temperature range. From 280 to $240^{\circ} \mathrm{C}$ (phase A), the polymer is in its amorphous melted phase. Around $240^{\circ} \mathrm{C}$, crystallization initiates and happens down to approximately $210^{\circ} \mathrm{C}$ (phase $\mathrm{B}$ ). The crystallization occurs at a higher temperature for higher pressure level, which has already been explored in the literature [28]. Finally, the matrix cools in its semi-crystalline phase from $210^{\circ} \mathrm{C}$ to room temperature (phase C). It appears that the specific volume is lower for higher pressure levels, which is due to the compressibility of the matrix.

\section{Identification of the coefficient of thermal expansion}

For a given pressure level, the specific volume variations $V_{s p e}$ are only due to thermal $\left(V_{T h}\right)$ and crystallization $\left(V_{C r}\right)$ contributions (Eq. 2). 


$$
V_{\text {spe }}=V_{T h}+V_{C r}
$$

When crystallization does not occur (in phases A and C), these variations therefore only depend on thermal contraction of the matrix. For a given temperature, the thermal contribution to the specific volume can be written as:

$$
V_{T h}(T)=V_{\text {spe }}\left(T_{0}\right)\left(1+\int_{T_{0}}^{T} \alpha_{V o l}(T) d T\right)
$$

where $T_{0}$ is the initial temperature of the melted matrix (i.e. $280^{\circ} \mathrm{C}$ ) and $\alpha \mathrm{Vol}$ is the volumetric coefficient of thermal expansion. From this relation and the evolution of the specific volume, it is possible to estimate the coefficient of thermal expansion of the matrix during phases A and C. They are represented in Fig. 4a, and compared with several values from the literature [24-27]. The same analysis protocol was applied to specific volume evolutions obtained by Zoller [28], leading to values also plotted in Fig. 4a. The evolution of $\alpha_{\mathrm{Vol}}$ with temperature is not trivial. During phase A its value decreases during cooling, from values of approximately $80010^{-6} \mathrm{~K}^{-1}$ at $280^{\circ} \mathrm{C}$ to $50010^{-6} \mathrm{~K}^{-1}$ at $240^{\circ} \mathrm{C}$. This decrease is easily explained by the diminution of the thermal agitation of the molecules during cooling, resulting in a lower coefficient of thermal expansion as the temperature decreases. During phase $\mathrm{C}$, its value first rises from approximately $60010^{-6} \mathrm{~K}^{-1}$ at $210^{\circ} \mathrm{C}$ to $70010^{-6}$ $\mathrm{K}^{-1}$ at $150^{\circ} \mathrm{C}$ and then sharply decrease during cooling to approximately $35010^{-6} \mathrm{~K}^{-1}$ at $50^{\circ} \mathrm{C}$. This rise observed around $150^{\circ} \mathrm{C}$ is also reported in Ecochard [24] and appears in the values exploited from Zoller [28]. It is attributed to the Brill transition of the PA66 [39], which consists in a rearrangement of the crystalline structure of the PA66 occurring between the crystallization and the glass transition of the PA66. The decrease then softens from 50 to $0^{\circ} \mathrm{C}$, according to values from the literature. This slower decrease is attributed to the glass transition of the material, leading to a more compact structure of the matrix.

No clear impact of the pressure level on the coefficient of thermal expansion could be observed from the measurements performed on the PvT-XT on the specified pressure range (between 20 and $40 \mathrm{MPa}$ ). However, the values of $\alpha_{\mathrm{Vol}}$ obtained from Zoller demonstrate that higher pressure levels lead to a lower coefficient of thermal expansion, which is due to the compressibility of the matrix and its lower possibility to expand when compressed. In the following, the impact of pressure on the coefficient of thermal expansion will be disregarded.

It is possible to fit the values of $\alpha$ in the amorphous state with a linear regression. The obtained evolution of $\alpha \mathrm{VolA}$ is given by (Eq. 4) and is plotted in Fig $4 \mathrm{~b}$ together with the measured values obtained for the different pressure levels.

$$
\alpha_{V o l A}(T)=a_{A} T+b_{A},
$$

where $\mathrm{T}$ is the temperature expressed in ${ }^{\circ} \mathrm{C}$ and the coefficients $a_{A}$ and $b_{A}$ can be found in Table 2.

The same methodology can be applied to the evolution of $\alpha$ in its semi-crystalline state. This evolution is however decomposed into four phases in order to reproduce the 
measured evolution. The obtained evolution named $\alpha_{V o l} S C$ is given in Eq. 5 and is also plotted in Fig. 4b.

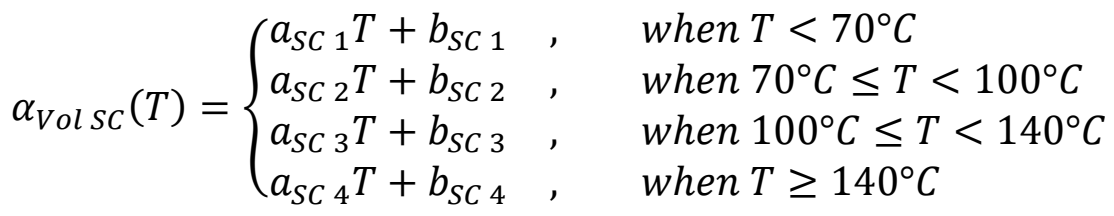

These temperature ranges were chosen so as to reproduce the evolution of the coefficient of thermal expansion through the $T_{g}$ and the Brill transition. The coefficients $a_{S C} i$ and $b_{S C} i$ can be found in Table 2 .

Values of $\alpha$ during crystallization are difficult to obtain. They are therefore extrapolated from its values in the amorphous and in the semi-crystalline states by considering a rule of mixture during crystallization (Eq. 6).

$$
\alpha_{V o l}(T)=\alpha_{V o l s C}(T)(C(T))+\alpha_{V o l A}(T)(1-C(T)),
$$

where $C(T)$ is the relative crystallinity. This latter has been obtained through DSC experiments under the same cooling conditions (i.e. $2 \mathrm{~K} \cdot \mathrm{min}^{-1}$ ). More details on DSC experiments can be found in [7,8]. The evolution of $\alpha_{V o l}$ with the temperature is plotted in Fig. 4b. Its variations are the same as the amorphous and the semi-crystalline contributions when temperature is higher than $250^{\circ} \mathrm{C}$ and inferior to $200^{\circ} \mathrm{C}$, respectively. During crystallization, it sharply rises at the beginning of crystallization (around $230^{\circ} \mathrm{C}$ ) following the evolution of the relative crystallinity.

Table 2: Characteristic values for the evolution of the matrix coefficient of thermal

\begin{tabular}{|c|c|c|}
\hline Characteristic & Unit & Value \\
\hline $\mathrm{a}_{\mathrm{A}}$ & $\left(K^{-2}\right)$ & $8.6510^{-6}$ \\
\hline$b_{A}$ & $\left(\mathrm{~K}^{-1}\right)$ & $-160010^{-6}$ \\
\hline $\operatorname{asc} 1$ & $\left(K^{-2}\right)$ & $2.2310^{-6}$ \\
\hline $\mathrm{bsc}_{\mathrm{sc}}$ & $\left(\mathrm{K}^{-1}\right)$ & $26010^{-6}$ \\
\hline $\operatorname{asc} 2$ & $\left(K^{-2}\right)$ & $2.7510^{-6}$ \\
\hline $\mathrm{b}_{\mathrm{SC} 2}$ & $\left(K^{-1}\right)$ & $22610^{-6}$ \\
\hline $\operatorname{asc} 3$ & $\left(\mathrm{~K}^{-2}\right)$ & $5.6810^{-6}$ \\
\hline $\mathrm{bsc}_{\mathrm{Sc}}$ & $\left(K^{-1}\right)$ & $-6810^{-6}$ \\
\hline $\operatorname{asc} 4$ & $\left(K^{-2}\right)$ & $-1.2910^{-6}$ \\
\hline
\end{tabular}
expansion. 


\begin{tabular}{lll}
$b_{s c 4}$ & $\left(K^{-1}\right) \quad 92010^{-6}$ \\
\hline
\end{tabular}

\section{Identification of the coefficient of crystallization shrinkage}

From the specific volume evolution, it is possible to calculate the strains underwent by the matrix during cooling thanks to (Eq. 7).

$$
\varepsilon_{T o t}=\frac{V_{S p e}(T)-V_{S p e}\left(T_{0}\right)}{V_{S p e}\left(T_{0}\right)}=\varepsilon_{T h}+\varepsilon_{C r}
$$

The evolution of this volumetric strain when the PA66 is submitted to a $20 \mathrm{MPa}$ pressure is represented in Fig. 5. Its variations are the same as the specific volume one described in Fig. 3, but it evolves from $0 \%$ at $280^{\circ} \mathrm{C}$ to $-16.5 \%$ at $30^{\circ} \mathrm{C}$.

From (Eq. 3), it is possible to calculate the thermal contribution to this train $\varepsilon T h$, which leads to

$$
\varepsilon_{T h}(T)=\int_{T_{0}}^{T} \alpha_{V o l}(T) d T
$$

The evolution of this thermal contribution to the total strain is also reported in Fig. 5. Except during crystallization, it perfectly fits the total strain evolution $\varepsilon T o t$.

According to (Eq. 7), subtracting this thermal contribution $\varepsilon T h$ to the total strain $\varepsilon T o t$ leads to the crystallization strain $\varepsilon_{C r}$. This strain is also represented in Fig. 5. No variations are observed outside crystallization, and the crystallization shrinkage is clearly identified between 230 and $210^{\circ} \mathrm{C}$. By considering a constant value of the coefficient of crystallization shrinkage $\beta_{\mathrm{Vol}}$, the value of $\varepsilon_{C r}$ obtained at $30^{\circ} \mathrm{C}$ therefore directly corresponds to $\beta_{V o l}$. The identified values of $\beta_{V o l}$ for the different pressure levels are summarized in table 3. Even though the shrinkage seems to increase with the pressure level, the uncertainty on these estimations do not permit to conclude on a possible impact of the pressure on the value of $\beta$ Vol.

Table 3: Identified values of the coefficient of crystallization shrinkage.

\begin{tabular}{llll} 
Pressure (MPa) & 20 & 30 & 40 \\
\hline$\beta_{\mathrm{Vol}}(\%)$ & $-2.7 \pm 0.3$ & $-2.8 \pm 0.3$ & $-2.9 \pm 0.3$ \\
\hline
\end{tabular}

\section{Bulk modulus estimation}

Then, as the matrix has been tested over the same temperature range under several pressure levels, the identification of its bulk modulus $K_{m}$ is possible through the investigation of its common expression: 


$$
K_{m}=-\left.V_{S p e} \frac{\partial P}{\partial V_{S p e}}\right|_{T, C}
$$

where $P$ is the pressure and the bar on the right means the temperature $T$ and relative crystallinity $C$ are constant over an infinitesimal pressure variation $\partial P$. From the measurements performed on the two extreme pressure levels, i.e. 20 and $40 \mathrm{MPa}$, and by considering the thermal contribution to the specific volume $V_{T h}$ it is possible to rewrite (Eq. 9) in its incremental form:

$$
\begin{aligned}
K_{m}(T)=-V_{T h} & \left.(T) \frac{\Delta P}{\Delta V_{T h}}\right|_{T} \\
& =-\left.V_{T h 20 M P a}(T) \frac{\Delta P}{V_{T h 40 M P a}-V_{T h 20 M P a}}\right|_{T}
\end{aligned}
$$

where $\Delta P=20 \mathrm{MPa}$, and $V_{T h} 40 \mathrm{MPa}$ corresponds to the thermal contribution to the specific volume measured under a $40 \mathrm{MPa}$ pressure level. The same protocol was applied for the two other pressure couples, i.e. $20 \mathrm{MPa}$ and $30 \mathrm{MPa}$ and $30 \mathrm{MPa}$ and $40 \mathrm{MPa}$. The obtained values of $K_{m}$ are represented in Fig. 6, together with several values from the literature [2123]. It has to be pointed that during crystallization the relative crystallinity is not identical for the different pressure levels at a given temperature, as pressure directly impacts the crystallization temperature. Therefore, Eq. 9 cannot be applied and no value of $K_{m}$ can be obtained over crystallization.

The bulk modulus values slightly rise from 1.40 to $1.96 \mathrm{GPa}$ between 280 and $240^{\circ} \mathrm{C}$, respectively. They are stable from 200 to $150^{\circ} \mathrm{C}$ and are close to $1.90 \mathrm{GPa}$. Then, it rises to $10 \mathrm{GPa}$ between 150 and $30^{\circ} \mathrm{C}$. This zone corresponds to the glass transition of the material $\left(T_{g}=63^{\circ} \mathrm{C}\right)$. The same methodology was applied to data from Wang et al. [40] in the molten amorphous state of the matrix, and from Zoller [28] over the whole temperature range. Values in the molten amorphous state are found in excellent agreement with results from the literature. According to the results from Zoller, the bulk modulus evolves almost linearly with the temperature from $280^{\circ} \mathrm{C}$ to $70^{\circ} \mathrm{C}$ and then rises to a value of $6 \mathrm{GPa}$ at $30^{\circ} \mathrm{C}$.

The bulk modulus values obtained from PvT-XT at temperatures lower than $T_{g}$ seem inconsistent with values from the literature, as these latter are comprised between 5.5 and $7 \mathrm{GPa}$ for temperature from 0 to $50^{\circ} \mathrm{C}$. This is explained by a difficulty of the PvT-XT to apply a hydrostatic pressure for low pressure levels when the temperature is below the $T_{g}$ of the polymer. The piston of the PvT-XT applies its load on the sample. As the temperature decreases below $T_{g}$, the polymer stiffness increases and it becomes harder to deform it in order to compress it against the inner cavity of the dilatometer. This leads to a higher value of $K_{m}$, as the strain is mainly due to a unidirectional compressive load. As a consequence, the values of $K_{m}$ obtained from the PvT-XT measurement has to be disregarded when the temperature is lower than $T_{g}$. Experiments performed under higher pressure levels should be preferred in the future, as was already demonstrated on another plunger-type volumetric dilatometer developed by the same research team [41]. To counteract this limitation, an interpolation function is proposed (Eq. 11), which is based on 
the results from PvT-XT measurements when the temperature is higher than $T_{g}$ and on values from literature for lower temperatures. As the values before and after crystallization are close, it is considered that the crystallization does not affect the value of $K_{m}$. The function detailed in (Eq. 11) is also plotted in Fig. 6.

$$
\left\{\begin{array}{l}
K_{m}(T)=K_{0}-\Delta K \cdot h_{m}(T)-K_{1} \cdot g_{m}(T) \\
h_{m}(T)=\tanh \left(d_{m} *\left(T-T_{m 2}\right)\right)
\end{array}\right.
$$

This function and the associated characteristics were chosen to best fit the experimental values and do not represent specific values of the material properties. The associated characteristics values are depicted in table 4.

Table 4: Characteristic values for the evolution of the matrix Young's modulus.

\begin{tabular}{lll} 
Characteristic & Unit & Value \\
\hline $\mathrm{K}_{0}$ & (GPa) & 4.7 \\
$\Delta \mathrm{K}$ & $(\mathrm{GPa})$ & 2.0 \\
$\mathrm{~K}_{1}$ & $(\mathrm{GPa})$ & 1 \\
$\mathrm{~d}_{\mathrm{m}}$ & & 0.025 \\
$\mathrm{~T}_{\mathrm{m} 2}$ & $\left({ }^{\circ} \mathrm{C}\right)$ & 70 \\
\hline
\end{tabular}

\section{Elastic properties estimation}

By considering the matrix is an isotropic and homogeneous material, it is possible to estimate its shear modulus $G_{m}$ and Poisson's ratio $v_{m}$ from the Young's and bulk moduli and thanks to relations (Eq. 12) and (Eq. 13).

$$
\begin{aligned}
G_{m} & =\frac{3 K_{m} E_{m}}{9 K_{m}-E_{m}} \\
v_{m} & =\frac{3 K_{m}-E_{m}}{6 K_{m}}
\end{aligned}
$$

The shear modulus obtained from (Eq. 12) is represented in Fig. 7, together with several values from literature $[14,17,18]$. The evolution of the shear modulus is sensibly identical as the Young's modulus one described earlier. The values obtained from the (Eq. 12) are in excellent agreement with values from the literature, thus comforting the employed method.

Finally, the estimation of the matrix Poisson's ratio $v_{m}$ is performed according to relation (Eq. 13). Its evolution is plotted in Fig. 8, together with the different identified elastic moduli, i.e. $E_{m}, K_{m}$ and $G_{m}$. 
The Poisson's ratio evolution is less trivial to describe than the other elastic moduli. It first decreases linearly between $200^{\circ} \mathrm{C}$ and $130^{\circ} \mathrm{C}$, from a value of 0.47 to 0.455 . A value close to 0.5 is commonly admitted for polymers in the molten state, as the shear and Young's moduli tend to a negligible value compared to the bulk modulus [42]. During the glass transition, the ratio rises at a maximum value of 0.46 at $75^{\circ} \mathrm{C}$ and then decreases to 0.43 at $35^{\circ} \mathrm{C}$. This rise, which may be attributed to the glass transition, might only be due to the use of several methods to obtain the Young's and bulk moduli and therefore might not represent an actual behavior of the material. Finally, $v_{m}$ slowly decreases to 0.42 at $50^{\circ} \mathrm{C}$. This value is correlated with results from the literature [43] where the Poisson's ratio of PA66 at $25^{\circ} \mathrm{C}$ is found to be 0.40 , even though it is often considered that Poisson's ratio of polymers reaches 0.33 at room temperature [42].

\section{Composite characterization}

The tensile tests performed on the composite material led to the stress-strain curves for the $\left[+45_{2}-45_{2}\right]$ s samples along their longitudinal and transversal direction, denoted by the subscripts $x$ and $y$, respectively. The averaged results for the three samples are represented in Fig. 9. The strain level along the $x$ direction is positive as it is submitted to a tensile load, whereas the strain along the $y$ direction is negative due to Poisson effect. For both strain directions, the stress $\sigma_{x x}$ first shows a transient behavior for small strains along both directions (from 0 to $500 \mu \varepsilon$ ) and then evolves linearly with the strain. The nonlinear part of the evolution will be disregarded in the material behavior identification, as it may be attributed to possible fiber re-alignment in the composite.

According to the classical lamination theory applied to linear elastic composite materials [44], it is possible to set a system of equations relating the stress $\sigma_{x x}$ and $\sigma_{y y}$ to the strains along the two main directions $\varepsilon_{x x}$ and $\varepsilon_{y y}$. These relations then depend on the mechanical properties of the elementary ply in its local base, i.e. $E_{L}, E_{T}, G_{L T}$ and $v_{L T}$. This system of equations is given in (Eq. 14).

$$
\begin{gathered}
0.25\left(E_{L}+E_{T}+2 v_{L T} E_{T}\right)\left(\varepsilon_{x x}+\varepsilon_{y y}\right)+G_{L T}\left(\varepsilon_{x x}-\varepsilon_{y y}\right) \Delta=\sigma_{x x} \Delta \\
0.25\left(E_{L}+E_{T}+2 v_{L T} E_{T}\right)\left(\varepsilon_{x x}+\varepsilon_{y y}\right)+G_{L T}\left(\varepsilon_{y y}-\varepsilon_{x x}\right) \Delta=\sigma_{y y} \Delta, \\
\text { with } \Delta=\left(1-\frac{E_{T}}{E_{L}} v_{L T}^{2}\right)
\end{gathered}
$$

As the samples are submitted to tensile load along the $x$ direction, the stress $\sigma_{y y}$ is considered as null. Analyzing these equations permits to determine the in-plane properties of the elementary ply. Subtracting the second line from the first line of (Eq. 14) leads to (Eq. 15).

$$
2 G_{L T}\left(\varepsilon_{x x}-\varepsilon_{y y}\right) \Delta=\sigma_{x x} \Delta
$$

Rearranging the terms in (Eq. 15) leads to 


$$
\begin{aligned}
G_{L T} & =0.5 \frac{\delta_{x x} \delta_{x y}}{\delta_{x y}-\delta_{x x}} \\
\text { with } \delta_{x x} & =\frac{\sigma_{x x}}{\varepsilon_{x x}} \text { and } \delta_{x y}=\frac{\sigma_{x x}}{\varepsilon_{y y}}
\end{aligned}
$$

In (Eq. 16), $\delta_{x x}$ and $\delta_{x y}$ correspond to the slope of the stress-strain curves, given in table 5.

Table 5: Identified slopes of the stress-strain curves for the $\left[+45_{2}-45_{2}\right]$ s ply sequences.

\begin{tabular}{lll} 
Slope & $\delta_{x x}$ & $\delta_{x y}$ \\
\hline Value $\left(10^{-3} \mathrm{MPa} / \mu \varepsilon\right)$ & $7.73 \pm 0.73$ & $-9.90 \pm 0.72$ \\
\hline
\end{tabular}

The value of the in-plane shear modulus obtained from (Eq. 14) is $G_{L T}=2.17 \pm 0.36$ $\mathrm{GPa}$, which is more than two times the value of the matrix shear modulus $G_{m}$ for the same temperature.

To complete the characterization of the in-plane Young moduli $E_{L}$ and $E_{T}$, DMA tests led to the evolution of these moduli with temperature. Results from the different samples are represented in Fig. $10 \mathrm{a}$ and b, respectively.

Results along the longitudinal direction are more scattered than in the transversal one. However, they remain around the mean value with up to a $10 \%$ difference, which is usual with DMA results. For both directions, the modulus decreases during heating, with a larger decrease during the glass transition. From glass transition to higher temperature levels, the moduli seem to evolve linearly with temperature. The glass transition temperature can be observed thanks to the peak value of $\tan \delta$. For both orientations, this temperature is close to $62^{\circ} \mathrm{C}$.

Finally, the CTE measured with the linear dilatometer on [90]8 samples from room temperature to $150^{\circ} \mathrm{C}$ is presented in Fig. 11. The transversal coefficient of thermal expansion $\alpha_{T}$ first rises from 20 to $60^{\circ} \mathrm{C}$, from value of $2810^{-6} \mathrm{~K}^{-1}$ to $4010^{-6} \mathrm{~K}^{-1}$. This is attributed to the rise in the matrix coefficient of thermal expansion over the same temperature range (see Fig. 4). It then decreases while the temperature rises, leading to a $3010^{-6} \mathrm{~K}^{-1}$ value at $150^{\circ} \mathrm{C}$. As the matrix softens when temperature is higher than $T_{g}$, its elastic modulus decreases. This phenomenon coupled with the presence of a low amount of fibers in the weft direction might explain the decrease in the lateral coefficient of thermal expansion.

The characterization of the matrix and the associated composite thermomechanical properties was performed thanks to three different devices (i.e. a DMA, a volumetric dilatometer and a linear dilatometer) from the room temperature up to a maximum temperature ranging from 150 to $300^{\circ} \mathrm{C}$. Some difficulties were met to identify the different 
properties, especially when the temperature is higher than the glass transition temperature. The matrix mechanical properties then soften, leading to possible creep of the matrix. This makes difficult the properties identification at higher temperatures. To overcome this limitation, a prediction method is proposed in the following section.

\section{Homogenization and prediction of the composite equivalent properties}

Numerous methods have been developed during the past forty years to estimate the equivalent mechanical properties of UD [44] and woven [35] composite materials. Simple rules of mixtures such as the Voigt and Reuss bounds have already proven their capacity to predict the effective properties of UD composites such as the longitudinal Young's modulus $E_{L}$ and the in-plane Poisson's ratio $v_{L T}$ for the first bound, and the transversal Young's modulus $E_{T}$ for the second bound. Other simple analytical models can be found to predict the in-plane shear modulus $G_{L T}[44,45]$ and the longitudinal and transversal coefficients of thermal expansion $\alpha_{L}$ and $\alpha_{T}$ [46]. These different expressions are gathered from (Eq. 17) to (Eq. 22) and depend on the composite fiber volume ratio $V_{f}$, the fibers Young modulus $E_{f}$, Poisson's ratio $v_{f}$, shear modulus $G_{f}$ and longitudinal coefficient of thermal expansion $\alpha_{L f}$, as well as the different properties of the matrix identified in the previous section. It has to be noted that the linear coefficient of thermal expansion of the matrix is considered to be one third of its volumetric coefficient of thermal expansion, i.e. $\alpha_{L m}=1 / 3 \alpha_{V o l m}$, as the glass fibers are considered to be composed of an isotropic material.

$$
\begin{gathered}
E_{L U D}=V_{f} E_{f}+\left(1-V_{f}\right) E_{m}, \\
E_{T U D}=\frac{E_{m} E_{f}}{\left(1-V_{f}\right) E_{f}+V_{f} E_{m}}, \\
v_{L T U D}=V_{f} v_{f}+\left(1-V_{f}\right) v_{m}, \\
G_{L T U D}=G_{m} \frac{G_{f}\left(1+V_{f}\right)+G_{m}\left(1-V_{f}\right)}{G_{f}\left(1-V_{f}\right)+G_{m}\left(1+V_{f}\right)}, \\
\alpha_{L U D}=\frac{E_{f} \alpha_{L f} V_{f}+E_{m} \alpha_{L m}\left(1-V_{f}\right)}{E_{f} V_{f}+E_{m}\left(1-V_{f}\right)}, \\
\alpha_{T U D}=\left(1+v_{m}\right) \alpha_{L m}\left(1-V_{f}\right)+\left(1+v_{f}\right) \alpha_{L f} V_{f}-\alpha_{L} v_{L T U D},
\end{gathered}
$$

The estimation of the same properties in the case of a quasi-UD composite is found rarer in the literature, and may be achieved by employing models adapted to woven composites. However, these latter are often more sophisticated than the analytical models exposed previously. A simple analytical model is therefore proposed to overcome this limitation. In the following, the warp and weft directions will be considered as composed of the same type of fibers and with identical linear weight. The quasi-UD reinforcement is defined according to its weight ratio $k$ (which corresponds to the ratio between the warp 
fibers weight and the total weight of the material), its area weight $A_{w}$ and the fiber density $\rho_{f}$. From these parameters and knowing the fiber volume fraction $V_{f}$, it is possible to estimate the thickness of the composite ply $e_{C}$. From the surface $S$, the fiber mass $m_{f}$ is:

$$
m_{f}=S A_{w}
$$

And the fiber volume $\mathrm{Vol}_{f}$ is given by

$$
V o l_{f}=\frac{m_{f}}{\rho_{f}},
$$

The total volume VolTot is given by

$$
\operatorname{Vol}_{T o t}=S e_{C}
$$

Therefore

$$
V_{f}=\frac{V o l_{f}}{V o l_{T o t}}=\frac{A_{w}}{\rho_{f} e_{C}}
$$

Which leads to

$$
e_{C}=\frac{A_{w}}{\rho_{f} V_{f}}
$$

The main assumption of the quasi-UD properties estimation is based on a simple representation of the quasi-UD structure as two UD plies at $0^{\circ}$ and $90^{\circ}$, thus representing the warp and weft directions, respectively (Fig. 9). These two plies have distinct thicknesses named $h_{w a}$ and $h_{w e}$ respectively which sum equals $e_{c}$. From these thicknesses, it is possible to express the weight ratio $k$ (Eq. 28).

$$
k=\frac{h_{w a}}{e_{C}}
$$

The mechanical behavior of both plies can be expressed through their thermomechanical properties: $E_{L i}, E_{T i}, v_{L T i}, G_{L T i}, \alpha_{L i}, \alpha_{T i}$, where the subscript $i=w a$ or $w e$. It will be considered in the following that both plies have the identical fiber volume fraction $V_{f}$. Therefore, their properties can be determined thanks to Eqs 17-22. As they are oriented along the $0^{\circ}$ and $90^{\circ}$ directions, some of their properties are identical, leading to $E_{L w a}=$ $E_{T w e}, E_{T w a}=E_{L w e}, G_{L T w a}=G_{L T w e}, v_{L T w a}=v_{L T w e}, \alpha_{L w a}=\alpha_{T w e}$ and $\alpha_{T w a}=\alpha_{L w e}$.

According to the Classical Lamination Theory [44,45], the constitutive law of a composite ply can be expressed as:

$$
\sigma_{i}=Q_{i j} \varepsilon_{j}
$$


where $\sigma_{i}, \varepsilon_{j}$ and $Q_{i j}$ are the components of the in-plane stress tensor, in-plane strain tensor, and reduced stiffness tensor, respectively, expressed in the global coordinate system. Relations between the components of the reduced stiffness tensor and the engineer moduli $E_{L}, E_{T}, v_{L T}$ and $G_{L T}$ is proposed in Appendice A. Based on expression (29) it is possible to estimate the equivalent properties of this ensemble of two plies, denoted by the subscript QUD for Quasi Uni-Directional. The methodology was proposed in [45] and leads to the relations:

$$
\begin{gathered}
E_{L Q U D}=\left(1-\gamma_{Q U D}\right) \gamma_{U D}\left(k E_{L U D}+(1-k) E_{T U D}\right), \\
E_{T Q U D}=\left(1-\gamma_{Q U D}\right) \gamma_{U D}\left(k E_{T U D}+(1-k) E_{L U D}\right), \\
v_{L T Q U D}=\frac{v_{L T U D}}{k+(1-k) \frac{E_{L U D}}{E_{T U D}}}, \\
G_{L T Q U D}=G_{L T U D},
\end{gathered}
$$

with

$$
\begin{gathered}
\gamma_{U D}=\frac{1}{1-\frac{E_{T U D}}{E_{L U D}} v_{L T U D}^{2}} \\
\gamma_{Q U D}=\frac{v_{L T U D}^{2}}{\left(k \frac{E_{T U D}}{E_{L U D}}+1-k\right)\left(k+(1-k) \frac{E_{T U D}}{E_{L U D}}\right)}
\end{gathered}
$$

The model proposed in [45] is however limited to the previous mechanical properties $E_{L Q U D}, E_{T Q U D}, v_{L T Q U D}$ and $G_{L T Q U D}$ and do not estimates the thermal expansion of the material. The authors therefore followed the same methodology but considered a thermo-mechanical constitutive law describing the behavior of each ply:

$$
\begin{aligned}
& \sigma_{i}=Q_{i j}\left(\varepsilon_{j}-\varepsilon_{j}^{t h}\right), \\
& \text { with } \varepsilon_{j}^{t h}=\alpha_{j} \Delta T
\end{aligned}
$$

The coefficients of thermal expansion were deduced from the classical lamination theory but lead to more complex formulations, as given in Eqs. 37-39. The detailed deduction of these equations is presented in Appendix B. 


$$
\begin{aligned}
\alpha_{L Q U D}=\left(E_{L U D}\right. & E_{T U D} h_{w a}^{2} \alpha_{L U D}-E_{L U D} E_{T U D} v_{L T U D} h_{w a} h_{w e} \alpha_{L U D} \\
& +E_{L U D} E_{T U D} h_{w e}^{2} \alpha_{T U D} \\
& +E_{L U D} E_{T U D} v_{L T U D} h_{w a} h_{w e} \alpha_{T U D} \\
& +E_{L U D}^{2} h_{w a} h_{w e} \alpha_{L U D}+E_{T U D}^{2} h_{w a} h_{w e} \alpha_{T U D} \\
& -E_{T U D}^{2} h_{w a}^{2} v_{L T U D}^{2} \alpha_{L U D}-E_{T U D}^{2} h_{w e}^{2} v_{L T U D}^{2} \alpha_{T U D} \\
& -E_{T U D}^{2} h_{w a} h_{w e} v_{L T U D}^{2} \alpha_{L U D} \\
& -E_{T U D}^{2} h_{w a} h_{w e} v_{L T U D}^{2} \alpha_{T U D} \\
& +E_{T U D}^{2} h_{w a} h_{w e} v_{L T U D} \alpha_{L U D} \\
& \left.-E_{T U D}^{2} h_{w a} h_{w e} v_{L T U D} \alpha_{T U D}\right) / \Delta_{Q U D} \\
\alpha_{T Q U D}=\left(E_{L U D}\right. & E_{T U D} h_{w a}^{2} \alpha_{T U D}-E_{L U D} E_{T U D} v_{L T U D} h_{w a} h_{w e} \alpha_{L U D} \\
& +E_{L U D} E_{T U D} h_{w e}^{2} \alpha_{L U D} \\
& +E_{L U D} E_{T U D} v_{L T U D} h_{w a} h_{w e} \alpha_{T U D} \\
& +E_{L U D}^{2} h_{w a} h_{w e} \alpha_{L U D}+E_{T U D}^{2} h_{w a} h_{w e} \alpha_{T U D} \\
& -E_{T U D}^{2} h_{w a}^{2} v_{L T U D}^{2} \alpha_{T U D}-E_{T U D}^{2} h_{w e}^{2} v_{L T U D}^{2} \alpha_{L U D} \\
& -E_{T U D}^{2} h_{w a} h_{w e} v_{L T U D}^{2} \alpha_{L U D} \\
& -E_{T U D}^{2} h_{w a} h_{w e} v_{L T U D}^{2} \alpha_{T U D} \\
& +E_{T U D}^{2} h_{w a} h_{w e} v_{L T U D} \alpha_{L U D} \\
& \left.-E_{T U D}^{2} h_{w a} h_{w e} v_{L T U D} \alpha_{T U D}\right) / \Delta_{Q U D} \\
&
\end{aligned}
$$

with

$$
\begin{gathered}
\Delta_{Q U D}=E_{L U D}^{2} h_{w a} h_{w e}+E_{L U D} E_{T U D} h_{w a}^{2}+E_{L U D} E_{T U D} h_{w e}^{2} \\
-E_{T U D}^{2} h_{w a}^{2} v_{L T U D}^{2}-2 E_{T U D}^{2} v_{L T U D}^{2} h_{w a} h_{w e} \\
+E_{T U D}^{2} h_{w a} h_{w e}-E_{T U D}^{2} v_{L T U D}^{2} h_{w e}^{2}
\end{gathered}
$$

The composite properties measured in the previous section can therefore be estimated thanks to these equations and considering the fiber properties are known. These latter correspond to glass fibers properties and are gathered in Table 6. 
Table 6: Thermomechanical properties of the glass fibers[44, 45].

\begin{tabular}{lll} 
Property & Unit & Value \\
\hline$E_{f}$ & (GPa) & 75 \\
$G_{f}$ & $(\mathrm{GPa})$ & 30 \\
$\mathrm{~K}_{f}$ & $(\mathrm{GPa})$ & 50 \\
$\mathrm{~V}_{f}$ & & 0.25 \\
$\alpha_{\mathrm{Lf}}$ & $\left(\mathrm{K}^{-1}\right)$ & $510^{-6}$ \\
\hline
\end{tabular}

The evolution of the estimated thermomechanical properties with temperature are represented in Fig. 13 a and b, for the elastic moduli $E_{L}, E_{T}, G_{L T}$, and $v_{L T}$ and the coefficients of thermal expansion $\alpha_{L}$ and $\alpha_{T}$, respectively. The fiber volume fraction is first fixed to $50 \%$, and the properties are computed versus temperature in the cases of a pure UD composite and a quasi UD composite with a value of $\mathrm{k}=0.95$ (thus corresponding to $95 \%$ of fibers along the warp direction as mentioned by Chomarat). The results experimentally obtained at $25^{\circ} \mathrm{C}$ for $G_{L T}$ are also represented on Fig. 13 a, as well as results obtained by Cazaux and Ramezani Dana et al. $[6,47]$ on unidirectional samples with the same materials, leading to $E_{L}=42.9 \pm 1.0 \mathrm{GPa}$ and $E_{T}=8.0 \pm 0.4 \mathrm{GPa}$. The impact of the fiber volume fraction $V_{f}$ is illustrated through the evolution of $E_{L}$ and $E_{T}$ as well as $\alpha_{L}$ and $\alpha_{T}$ as a function of temperature for three different values of $V_{f}(30,50$ and $70 \%)$ in figure $13 \mathrm{c}$ and $\mathrm{d}$, respectively.

As experimentally measured, the evolution of the elastic modulus $E_{L}, E_{T}$ and $G_{L T}$ show a slight decrease with temperature in both the UD and the Quasi UD cases. The decrease is more important around $50^{\circ} \mathrm{C}$ as the temperature rises above the glass transition temperature of the material. Both the $E_{T}$ and $G_{L T}$ tend to a negligible value at high temperature due to the melting of the matrix. The values of $E_{L}$ remain in a higher value range as this property is mainly driven by the fiber properties in the developed model. Considering the quasi UD nature of the material, the in-plane shear modulus $G_{L T}$ does not changes, but the transversal modulus $E_{T}$ increases while the longitudinal modulus decreases. This is due to the difference in the distribution of the fibers: a lower amount of fibers is present in the longitudinal direction leading to a lower value of $E_{L}$. This amount is located along the weft direction thus improving the value of $E_{T}$. The values estimated at $25^{\circ} \mathrm{C}$ for these three properties are in excellent agreement with the one obtained experimentally in the previous section, showing less than $15 \%$ difference.

The longitudinal CTE is slightly evolving with temperature, as this direction is mainly driven by the fiber properties. It remains quite constant around a value close to the fiber linear CTE $\alpha_{L f}$. The influence of the reinforcement architecture on this property is negligible and will not be discussed. The transversal CTE is much more sensitive to both the temperature and the nature of the reinforcement. In the case of the pure UD the lateral expansion is driven by the matrix. As a consequence, the evolution of $\alpha_{T}$ follows the ones 
of $\alpha_{m}$ that were described in section 3.1. In the case of the quasi UD, this evolution is more altered. The CTE first rises from $3010^{-6} \mathrm{~K}^{-1}$ at $-100^{\circ} \mathrm{C}$ to $5010^{-6} \mathrm{~K}^{-1}$ at $45^{\circ} \mathrm{C}$. It then slightly decreases around $T_{g}$ due to the softening of the matrix. The evolution is then similar to the UD case, leading to an increase in the value of $\alpha_{T}$ until $140^{\circ} \mathrm{C}$ due to the Brill transition, followed by a decrease as the temperature approaches the melting temperature. The peak value of $\alpha_{T}$ around the Brill transition is however much lower in the quasi UD case compared to the UD one, with values of $6710^{-6}$ and $15210^{-6} \mathrm{~K}^{-1}$, respectively. It seems that the presence of a little amount of fibers along the weft direction highly impacts the transversal coefficient of thermal expansion.

The fiber volume fraction has a common impact on the material properties (Fig. 13 c and d). A higher fiber volume fraction leads to higher moduli $\left(E_{L}\right.$ and $\left.E_{T}\right)$, and to lower coefficients of thermal expansion $\left(\alpha_{L}\right.$ and $\left.\alpha_{T}\right)$. It has to be noted that on the whole range of $V_{f}$, the longitudinal CTE remains lower than $13.110^{-6} \mathrm{~K}^{-1}$, which is close to the glass fiber CTE. Therefore, the thermal expansion of the composite mostly occurs in the transversal direction.

For both the [0]8 and [90]8 samples tested on DMA, the measured longitudinal and transversal moduli are represented in Fig. 14 together with their estimated values. The fiber volume fraction was considered to be $35 \%$ and $44 \%$ for the longitudinal and transversal moduli, respectively, and the impact of the uncertainty on these values is also plotted in Fig. 14. The estimated value of $E_{L}$ and $E_{T}$ present a good correlation with the order of magnitude of the experimentally measured ones. For both moduli, the estimated properties overvalue the measured properties. Concerning the longitudinal modulus, the estimated value is closer to the experimental one around $25^{\circ} \mathrm{C}$ than at higher temperature. The estimated value decreases less with the temperature than the measured ones. This difference is explained by the analysis performed on the DMA values. During three point bending experiments, samples are submitted to tensile and compression together with possible shear. The analysis of DMA results is based on the Euler-Bernoulli approach, which does not consider shear [48]. Therefore, the measured modulus is in fact an apparent modulus which relies on both the evolution of $E_{L}$ and $G_{L T}$. This latter modulus is mainly driven by the matrix stiffness, which highly decreases through the glass transition temperature (Fig. 13a). The measured modulus is therefore impacted by this evolution and decreases more than the estimated modulus. Thinner samples should be used to overcome this effect $[48,49]$, but this may lead to higher uncertainties due to the thickness uncertainty. Further experiments should be performed but they remain an outlook of the presented work. The evolution of the measured transversal modulus is more accurately estimated thanks to the developed model, even though the estimated moduli is higher than the measured one by approximately $1 \mathrm{GPa}$.

The measured and estimated CTEs are plotted in Fig. 15. Their evolutions were previously discussed. It appears that the UD model largely overestimates the measured $\mathrm{CTE}$, its value at $25^{\circ} \mathrm{C}$ being two times the measured one, and this difference continuously increases with temperature until $150^{\circ} \mathrm{C}$ where the estimated value is six times higher than the measured one. The Quasi UD model also overestimates the coefficient value, but is closer to it as it never exceeds 2.5 times the experimental value. It has however to be noted that once the temperature is higher than $T_{g}$, the measurement of the CTE is more complex 
leading to uncertain values of the CTE. Therefore, after $80^{\circ} \mathrm{C}$, the measured values would preferably be disregarded. To overcome this limitation, contactless measurements [50] should be performed to avoid creep of the material.

It appears that even in the case of a slightly quasi unidirectional composite, with only $5 \%$ of fibers along the weft direction, the UD estimation of the transversal coefficient of thermal expansion cannot be used to predict the material thermomechanical properties. This property is of primary importance in the study of residual stresses during manufacturing of composites, and mainly drives their development. The use of the developed QUD model would therefore improve the accuracy of such prediction when a characterization of the material properties over the whole temperature range is not possible.

\section{Conclusions}

This study proposes an investigation in the thermomechanical behavior of a low viscosity PA66 matrix and the associated continuous glass fiber reinforced composite over a large temperature range (from 20 to $280^{\circ} \mathrm{C}$ ). The matrix was first characterized thanks to a DMA, leading to an estimation of its Young's modulus $E_{m}$ and its evolution with temperature. Then, a PvT-XT volumetric dilatometer was employed to obtain the evolution of the matrix specific volume with temperature. From these values, the coefficient of thermal expansion of the matrix $\alpha_{m}$ was identified over the whole temperature range, as well as the coefficient of crystallization shrinkage $\beta_{m}$. The bulk modulus $K_{m}$ was also determined but its identification was limited to the temperature higher than $T_{g}$. Experiments performed at higher pressure level should prevent such a limitation. Finally, the shear modulus $G_{m}$ was estimated from the values of $E_{m}$ and $K_{m}$. These different properties and their evolution with temperature were compared with numerous values from the literature, showing an excellent agreement. This demonstrates the ability of the developed experimental method to provide accurate results through the use of only two devices (a DMA and the PvT-XT), when at least three were previously necessary (e.g. a DMA, a torsion pendulum and a volumetric dilatometer).

A continuous glass fiber reinforced composite based on the same matrix was also investigated. Tensile tests at room temperature led to its in-plane elastic moduli, i.e. its longitudinal and transversal Young's moduli $E_{L}$ and $E_{T}$, as well as its shear modulus $G_{L T}$. This was completed with DMA tests, which led to the evolution of the Young's moduli $E_{L}$ and $E_{T}$ with temperature. Finally, a dilatometer permitted to monitor the evolution of the transversal coefficient of thermal expansion $\alpha_{T}$. Facing the difficulty to correctly measure the composite properties at temperatures higher than $T_{g}$, an estimation model is extended. It is based on the classical lamination theory and considers quasi-unidirectional reinforcement as two independent layer of $0^{\circ}$ and $90^{\circ}$ orientations, representing the warp and weft fibers, respectively. The estimated values are of the same order of magnitude as the measured ones. The elastic moduli obtained by DMA are overestimated by the model when the ones obtained by tensile tests are underestimated. The measured transversal coefficient of thermal expansion $\alpha_{T}$ is also overestimated by the developed model. However, this latter leads to values closer to the experimental ones compared to standard estimation model developed for unidirectional materials. This demonstrates the better 
ability of the developed model to reproduce the thermomechanical behavior of the quasiunidirectional material.

\section{Funding}

This study is part of the COMPETH project supported and funded by IRT Jules Verne (French Institute in Research and Technology in Advanced Manufacturing, Technologies for Composite, Metallic and Hybrid Structures).

\section{Aknowledgements}

The authors wish to associate the industrial partners of this project; respectively Airbus Group, Airbus Group Innovations, Daher and Solvay.

\section{Conflict of Interest}

The authors declare that they have no conflict of interest.

\section{References}

[1] M.F. Arif, N. Saintier, F. Meraghni, J. Fitoussi, Y. Chemisky, G. Robert, Multiscale fatigue damage characterization in short glass fiber reinforced polyamide-66, Compos. Part B Eng. 61 (2014) 55-65.

[2] D. Teixeira, M. Giovanela, L.B. Gonella, J.S. Crespo, Influence of injection molding on the flexural strength and surface quality of long glass fiber-reinforced polyamide 6.6 composites, Mater. Des. 85 (2015) 695-706.

[3] E. Lafranche, P. Krawczak, J.P. Ciolczyk, J. Maugey, Injection moulding of long glass fiber reinforced polyamide 66: Processing conditions/microstructure/flexural properties relationship, Adv. Polym. Technol. J. Polym. Process. Inst. 24 (2005) 114-131.

[4] P.P. Parlevliet, H.E.N. Bersee, A. Beukers, Residual stresses in thermoplastic composites-A study of the literature-Part I: Formation of residual stresses, Compos. Part A Appl. Sci. Manuf. 37 (2006) 1847-1857. doi:10.1016/j.compositesa.2005.12.025.

[5] P.P. Parlevliet, H.E.N. Bersee, A. Beukers, Residual stresses in thermoplastic composites - a study of the literature. Part III: Effects of thermal residual stresses, Compos. Part A Appl. Sci. Manuf. 38 (2007) 1581-1596. doi:10.1016/j.compositesa.2006.12.005.

[6] G. Cazaux, Faisabilité des procédés LCM pour l'élaboration de composites renfort continu à matrice thermoplastique polyamide, $\mathrm{PhD}$ Thesis, Université du Havre, France, 2016.

[7] J. Faraj, Analyse thermocinétique de la cristallisation en milieu confiné d'un composite à base d'une résine thermoplastique (Polyamide 66), PhD Thesis, Université de Nantes, France, 2016.

[8] J. Faraj, N. Boyard, B. Pignon, J.L. Bailleul, D. Delaunay, G. Orange, Crystallization kinetics of new low viscosity polyamides 66 for thermoplastic 
composites processing, Thermochim. Acta. $624 \quad$ (2016) 27-34. doi:10.1016/j.tca.2015.11.025.

[9] J. Faraj, B. Pignon, J.L. Bailleul, N. Boyard, D. Delaunay, G. Orange, Heat Transfer and Crystallization Modeling during Compression Molding of Thermoplastic Composite Parts, Key Eng. Mater. 651-653 (2015) 1507-1512. doi:10.4028/www.scientific.net/KEM.651-653.1507.

[10] I. Baran, K. Cinar, N. Ersoy, R. Akkerman, J.H. Hattel, A Review on the Mechanical Modeling of Composite Manufacturing Processes, Arch. Comput. Methods Eng. 24 (2017) 365-395. doi:10.1007/s11831-016-9167-2.

[11] C.W. Deeley, A.E. Woodward, J.A. Sauer, Effect of Irradiation On Dynamic Mechanical Properties of 6-6 Nylon, J. Appl. Phys. 28 (1957) 1124-1130. doi:10.1063/1.1722591.

[12] A.E. Woodward, J.M. Crissman, J.A. Sauer, Investigations of the Dynamic Mechanical Properties of Some Polyamides, J. Polym. Sci. 44 (1960) 23-34.

[13] J.H. Dumbleton, T. Murayama, On the dynamic mechanical behavior of nylon 66, Kolloid-Zeitschrift Und Zeitschrift Für Polym. 238 (1969) 410-415.

[14] W.P. Leung, K.H. Ho, C.L. Choy, Mechanical Relaxations and Moduli of Oriented Nylon 66 and Nylon 6, J. Polym. Sci. Part B Polym. Phys. 22 (1984) 1173-1191.

[15] N. Klein, G. Marom, A. Pegoretti, C. Migliaresi, Determining the role of interfacial transcrystallinity in composite materials by dynamic mechanical thermal analysis, Composites. 26 (1995) 707-712.

[16] R.L.J. Clark, M.D. Craven, R.G. Kander, Nylon 66 / poly ( vinyl pyrrolidone ) reinforced composites : 2 - Bulk mechanical properties and moisture effects, Compos. Part A Appl. Sci. Manuf. 30 (1999) 37-48.

[17] K. Schmieder, K. Wolf, Mechanische Relaxationserscheinungen an Hochpolymeren, Kolloid Zeitschrift. 134 (1953) 149-189.

[18] E.G. Bobalek, J. Lacson, W.R. Dawson, Microstructure of cold fracture sections as an indication of changes in properties of injection-molded nylon polymers, J. Appl. Polym. Sci. 3 (1960) 113-117.

[19] E. Jones Parry, D. Tabor, High-Pressure Torsion Pendulum for Viscoelastic Studies on Polymers., J. Phys. D. Appl. Phys. 6 (1973) 1328-1335. doi:10.1088/00223727/6/11/307.

[20] Z.A. Mohd Ishak, J.P. Berry, Effect of moisture absorption on the dynamic mechanical properties of short carbon fiber reinforced nylon 6,6, Polym. Compos. 15 (1994) 223-230. doi:10.1002/pen.760342202.

[21] R.W. Warfield, Compressibility of Bulk Polymers, Polym. Eng. Sci. 6 (1966) 176180 .

[22] K. Wei, J.A. Cuculo, D.W. Ihm, Effects of Pressure on the Compressibility and Crystallization of Fiber-Forming Polymers, J. Polym. Sci. Part B Polym. Phys. 21 (1983) 1091-1101.

[23] N. Lagakos, J. Jarzynski, J.H. Cole, J.A. Bucaro, Frequency and temperature dependence of elastic moduli of polymers, J. Appl. Phys. 59 (1986) 4017-4031. doi:10.1063/1.336707.

[24] F. Ecochard, Proprietes de Dilatation Thermique des Polyamides, J. Polym. Sci. 6 (1951) 601-608.

[25] P.S. Wilson, Thermal Expansion and Differential Scanning Calorimetry Phenomena 
in the y-Relaxation Region $\left(=150^{\circ} \mathrm{K}\right.$ ) of Nylon 6,6, Nylon 11, and Ethylene-co(Vinyl acetate), Macromolecules. 6 (1973) 914-918.

[26] K. Van De Velde, P. Kiekens, Thermoplastic polymers: Overview of several properties and their consequences in flax fibre reinforced composites, Polym. Test. 20 (2001) 885-893. doi:10.1016/S0142-9418(01)00017-4.

[27] C.L. Choy, W.P. Leung, E.L. Ong, Thermal expansivity of oriented nylon-6 and nylon-6,6, Polymer (Guildf). $26 \quad$ (1985) 884-888. doi:10.1016/00323861(85)90132-6.

[28] P. Zoller, D. Walsh, Standard Pressure-Volume-Temperature Data for Polymers, Technomic Publishing AG, Basel, 1995.

[29] B. Pignon, X. Tardif, N. Lefèvre, V. Sobotka, N. Boyard, D. Delaunay, A new PvT device for high performance thermoplastics: Heat transfer analysis and crystallization kinetics identification, Polym. Test. 45 (2015) 152-160. doi:10.1016/j.polymertesting.2015.05.013.

[30] G. Jeronimidis, a. T. Parkyn, Residual Stresses in Carbon Fibre-Thermoplastic Matrix Laminates, J. Compos. Mater. 22 (1988) 401-415. doi:10.1177/002199838802200502.

[31] T.J. Chapman, J.W. Gillespie, R.B. Pipes, J.-A.E. Manson, J.C. Seferis, Prediction of Process-Induced Residual Stresses in Thermoplastic Composites, J. Compos. Mater. 24 (1990) 616-643. doi:10.1177/002199839002400603.

[32] W.E. Lawrence, J.C. Seferis, Material response of a semicrystalline thermoplastic polymer and composite in relation to process cooling history, Polym. Compos. 13 (1992) 86-96.

[33] P. Sunderland, W. Yu, J.-A.E. Manson, A thermoviscoelastic analysis of processinduced internal stresses in thermoplastic matrix composites, Polym. Compos. 22 (2001) 579-592. doi:10.1002/pc.10561.

[34] J.A. Barnes, G.E. Byerly, The formation of residual stresses in laminated thermoplastic composites, Compos. Sci. Technol. 51 (1994) 479-494.

[35] L. Onal, S. Adanur, Modeling of Elastic, Thermal, and Strength/Failure Analysis of Two-Dimensional Woven Composites-A Review, Appl. Mech. Rev. 60 (2007) 37. doi:10.1115/1.2375143.

[36] Z. Hashin, S. Shtrikman, A variational approach to the theory of the elastic behaviour of multiphase materials, J. Mech. Phys. Solids. 11 (1963) 127-140. doi:10.1016/0022-5096(63)90060-7.

[37] L.L. Mishnaevsky, S. Schmauder, Continuum Mesomechanical Finite Element Modeling in Materials Development: A State-of-the-Art Review, Appl. Mech. Rev. 54 (2001) 49. doi:10.1115/1.3097288.

[38] ISO, IEC, BIPM, OIML, Guide to the expression of uncertainty in measurement, Geneva, Switzerland, 1995.

[39] A.Y. Feldman, E. Wachtel, G.B.M. Vaughan, A. Weinberg, G. Marom, The Brill Transition in Transcrystalline Nylon-66, 66 (2006) 4455-4459.

[40] Y.Z. Wang, W.J. Chia, K.H. Hsieh, H.C. Tseng, Specific Volume of Molten Thermoplastic Polymer Composite at High Pressure, (n.d.) 1731-1736.

[41] M. Péron, V. Sobotka, N. Boyard, S. Le Corre, Bulk modulus evolution of thermoset resins during crosslinking: Is a direct and accurate measurement possible?, J. Compos. Mater. 51 (2017) 463-477. doi:10.1177/0021998316647119. 
[42] P.H. Mott, J.R. Dorgan, C.M. Roland, The bulk modulus and Poisson's ratio of "incompressible" materials, J. Sound Vib. 312 (2008) 572-575. doi:10.1016/j.jsv.2008.01.026.

[43] N. Sato, T. Kurauchi, S. Sato, O. Kamigaito, Mechanism of fracture of short glass fibre-reinforced polyamide thermoplastic, J. Mater. Process. Technol. 19 (1984) $1145-1152$.

[44] C.T. Herakovich, Mechanics of fibrous composites, John Wiley \& Sons, 1998.

[45] J.-M. Berthelot, Matériaux composites - Comportement mécanique et analyse des structures, TEC\&DOC, Paris, 1999.

[46] R.A. Schapery, Thermal expansion coefficients of composite materials based on energy principles, J. Compos. Mater. 2 (1968) 380-404.

[47] H. Ramezani Dana, M. Gomina, J. Bréard, G. Orange, Mechanical behaviour of glass fiber weaven UD / high fluidity PA-based polymers for automotive applications, in: 19th ESAFORM Conf. Mater. Form., 2016: pp. 0200011-0200016. doi: $10.1063 / 1.4963405$.

[48] G. Swaminathan, K. Shivakumar, A Re-examination of DMA Testing of Polymer Matrix Composites, J. Reinf. Plast. Compos. 28 (2009) 979-994. doi: $10.1177 / 0731684407087740$.

[49] G. Tolf, P. Clarin, Comparison between flexural and tensile modulus of fibre composites, Fibre Sci. Technol. 21 (1984) 319-326.

[50] M. Péron, R. Cardinaud, N. Lefèvre, J. Aubril, V. Sobotka, N. Boyard, S. Le Corre, PvT-HADDOC: A multi-axial strain analyzer and cure monitoring device for thermoset composites characterization during manufacturing, Compos. Part A Appl. Sci. Manuf. 101 (2017). doi:10.1016/j.compositesa.2017.06.004.

\section{Appendix A}

For a unidirectional ply, the reduced stiffness tensor components $Q_{i j}$ can be expressed as a function of the engineering moduli $E_{L}, E_{T}, v_{L T}$ and $G_{L T}$ :

$$
\begin{gathered}
Q_{11}=\frac{E_{L}}{1-\frac{E_{T}}{E_{L}} v_{L T}^{2}} \\
Q_{22}=\frac{E_{T}}{1-\frac{E_{T}}{E_{L}} v_{L T}^{2}} \\
Q_{12}=Q_{21}=\frac{E_{T} v_{L T}}{1-\frac{E_{T}}{E_{L}} v_{L T}^{2}} \\
Q_{66}=G_{L T}
\end{gathered}
$$




\section{Appendix B}

For a unidirectional ply, the constitutive law is given by Eq. 36. The studied material is considered to be composed of two layers, one corresponding to the warp and one to the weft direction. The behavior of each layer is also described thanks to Eq. 36, but their properties differ. If we consider they are composed of the same material with identical fiber volume fraction, we can write that $E_{L w a}=E_{T w e}=E_{L U D}, E_{T w a}=E_{L w e}=E_{T U D}, G_{L T w a}=G_{L T w e}$ $=G_{L T} U D, v_{L T w a}=v_{L T w e}=v_{L T} U D, \alpha_{L w a}=\alpha_{T w e}=\alpha_{L U D}$ and $\alpha_{T w a}=\alpha_{L w e}=\alpha_{T} U D$. According to Appendix A and Eq. 34, one gets for the warp direction:

$$
\begin{gathered}
Q_{11 w a}=\gamma_{U D} E_{L U D} \\
Q_{22 w a}=\gamma_{U D} E_{T U D} \\
Q_{66 w a}=G_{L T U D} \\
Q_{12 w a}=\gamma_{U D} v_{L T U D} E_{T U D} \\
Q_{16 w a}=Q_{26 w a}=0
\end{gathered}
$$

And for the weft direction:

$$
\begin{gathered}
Q_{11 w e}=\gamma_{U D} E_{T U D} \\
Q_{22 w e}=\gamma_{U D} E_{L U D} \\
Q_{66 w e}=G_{L T U D} \\
Q_{12 w e}=\gamma_{U D} v_{L T U D} E_{T U D} \\
Q_{16 w e}=Q_{26 w e}=0
\end{gathered}
$$

The thermal expansion strains for both directions are given by:

$$
\begin{aligned}
& \varepsilon_{1 w a}^{t h}=\alpha_{L} \Delta T \\
& \varepsilon_{2 w a}^{t h}=\alpha_{T} \Delta T \\
& \varepsilon_{1 w e}^{t h}=\alpha_{T} \Delta T \\
& \varepsilon_{2 w e}^{t h}=\alpha_{L} \Delta T
\end{aligned}
$$

According to [45], the equivalent constitutive law is obtained as the mean expression over the whole laminate thickness: 


$$
\sigma_{i e q}=Q_{i j e q}\left(\varepsilon-\varepsilon_{j e q}^{t h}\right)=\frac{1}{e_{c}} \int_{-e_{c} / 2}^{+e_{c} / 2} \sigma_{i}(z) d z
$$

Where $\sigma_{i}(z)$ correspond to the component $i$ of the stress tensor at the depth $z$. This leads to the equivalent reduced stiffness tensor $Q_{i j e q}$ :

$$
Q_{i j e q}=\frac{1}{e_{c}}\left[h_{w a} Q_{i j w a}+h_{w e} Q_{i j w e}\right]
$$

And to the equivalent thermal stress component $\sigma^{\text {th }}{ }_{\text {ieq }}$ :

$$
\sigma_{i e q}^{t h}=Q_{i j e q} \varepsilon_{j e q}^{t h}=\frac{1}{e_{c}}\left[h_{w a} Q_{i j w a} \varepsilon_{i w a}^{t h}+h_{w e} Q_{i j w e} \varepsilon_{i w e}^{t h}\right]
$$

Substituting Eq. 28 in Eqs. B16 and B17 leads to:

$$
\begin{gathered}
Q_{i j e q}=\left[k Q_{i j w a}+(1-k) Q_{i j w e}\right] \\
Q_{i j e q} \varepsilon_{j e q}^{t h}=\left[k Q_{i j w a} \varepsilon_{i w a}^{t h}+(1-k) Q_{i j w e} \varepsilon_{i w e}^{t h}\right]
\end{gathered}
$$

The equivalent thermal strain can therefore be written as:

$$
\varepsilon_{j e q}^{t h}=\alpha_{j e q} \Delta T=Q_{i j e q}^{-1}\left[k Q_{i j w a} \varepsilon_{i w a}^{t h}+(1-k) Q_{i j w e} \varepsilon_{i w e}^{t h}\right]
$$

Then, from Appendix A and Eq. B18, it is possible to obtain the expressions of $E_{L Q U D}, E_{T}$ $Q U D, G_{L T} Q U D$ and $v_{L T} Q U D$ given in Eqs. 30-35. Finally, from Eq. B20, one can get to the expressions of $\alpha \mathrm{L}$ QUD and $\alpha \mathrm{T}$ QUD given in Eqs. 37-39. This was performed thanks to the Symbolic Toolbox in Matlab R2016a.

\section{Figures}

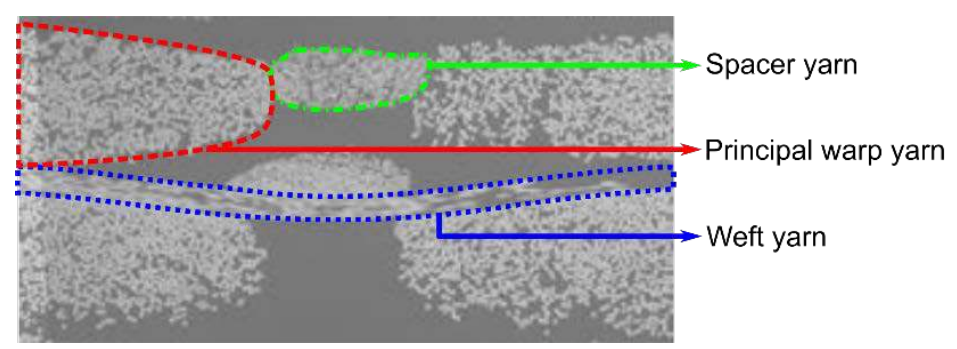

Figure 1. Reinforcement architecture. Light grey zones correspond to fibres and dark grey zones to the matrix. 


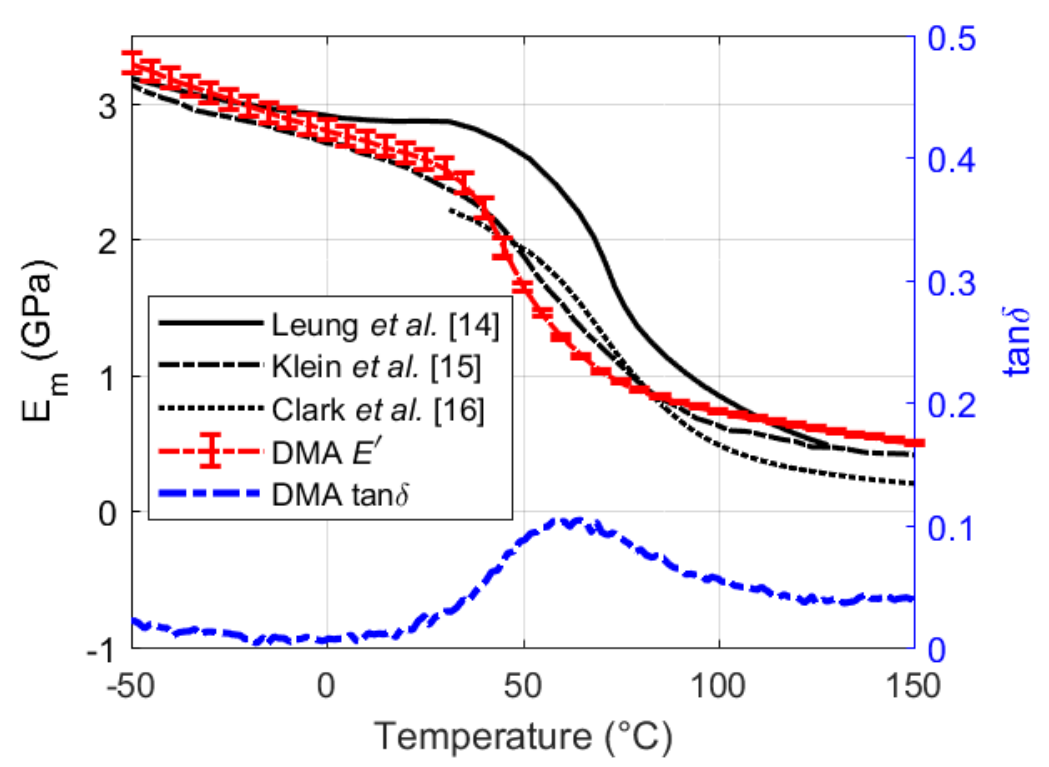

Figure 2. Evolution of the storage modulus E' and loss tangent tan $\delta$ with temperature from DMA measurements, compared with several values from the literature [14-16].

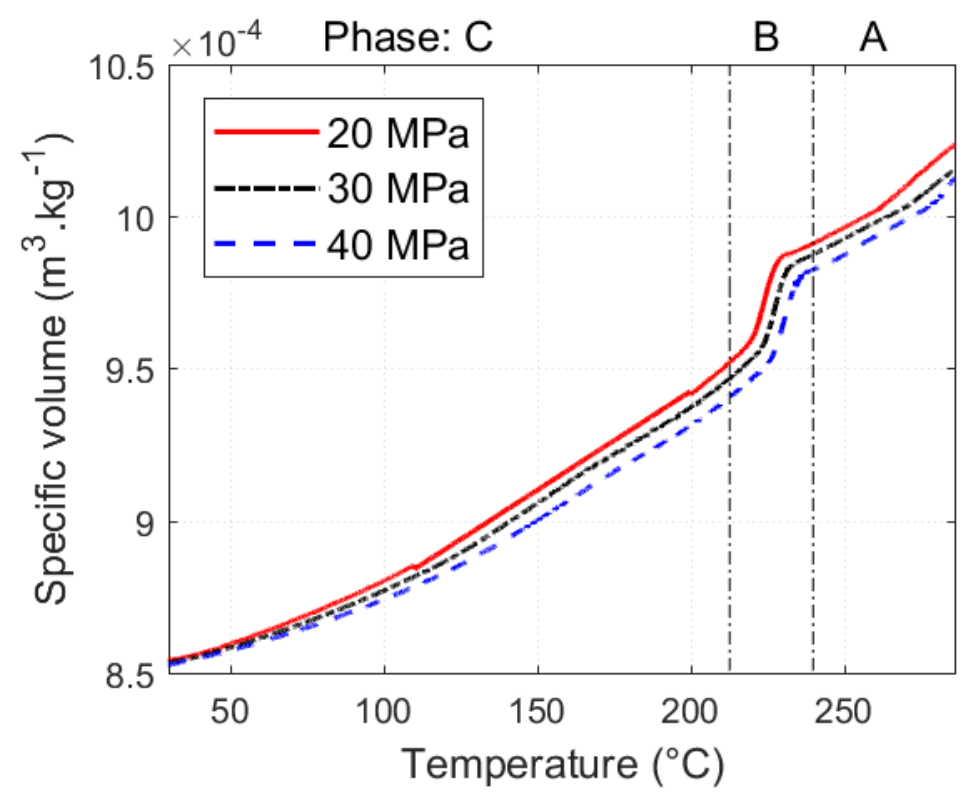

Figure 3. Evolution of the neat matrix specific volume from PvT-XT for different pressure level as a function of the temperature. 

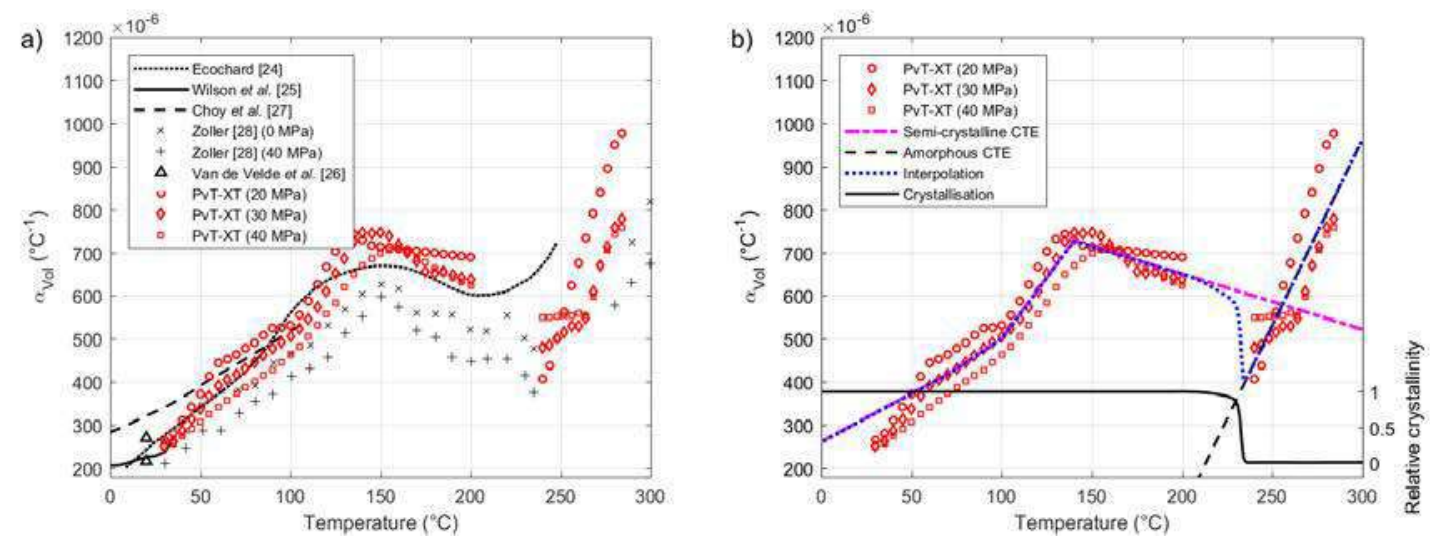

Figure 4. Evolution of the coefficient of thermal expansion of the PA66 from the PvT-XT experiments. (a) Compared with several values from the literature [24-28] (b) Compared with the proposed evolutions.

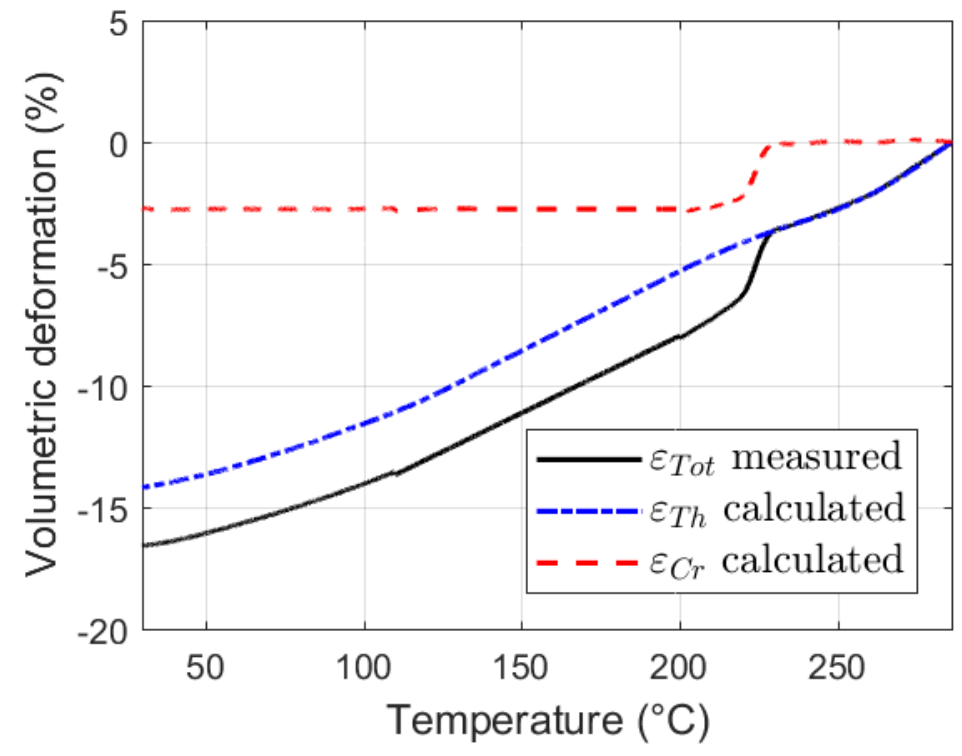

Figure 5. Evolution of the total volumetric strain $\varepsilon$ Tot of the PA66 submitted to a $20 \mathrm{MPa}$ pressure, together with the calculated thermal and crystallization strains, $\varepsilon \mathrm{Th}$ and $\varepsilon \mathrm{Cr}$, respectively. 


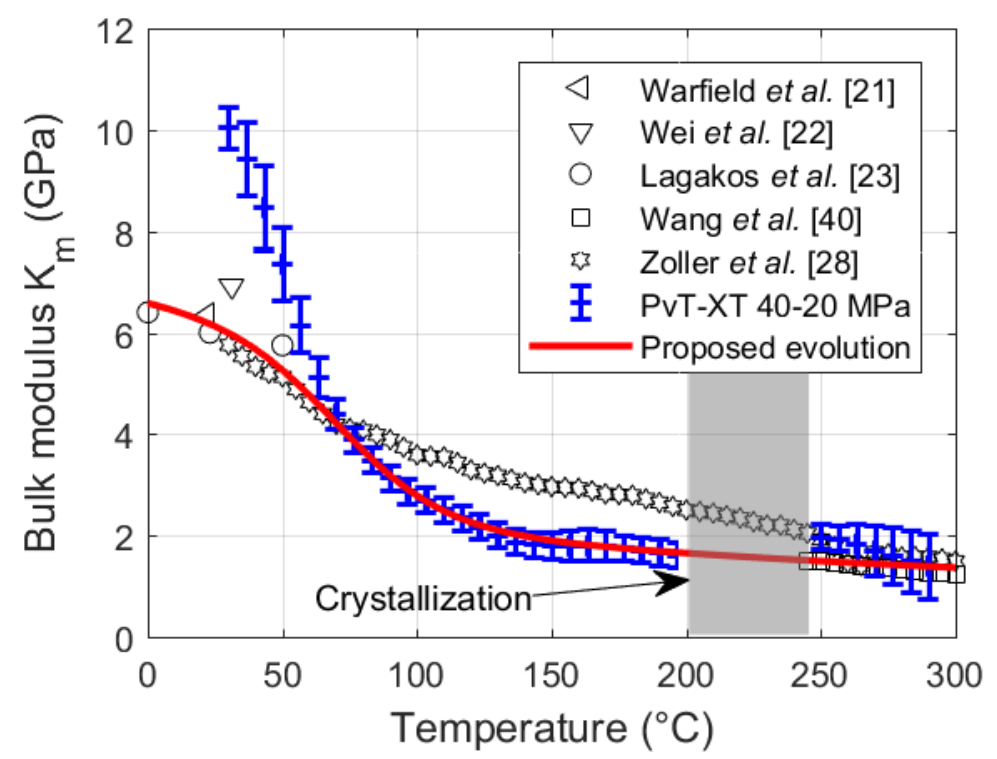

Figure 6. Evolution of the bulk modulus of the PA66 obtained with the PvT-XT and compared with several values from the literature [21-23,28,40]

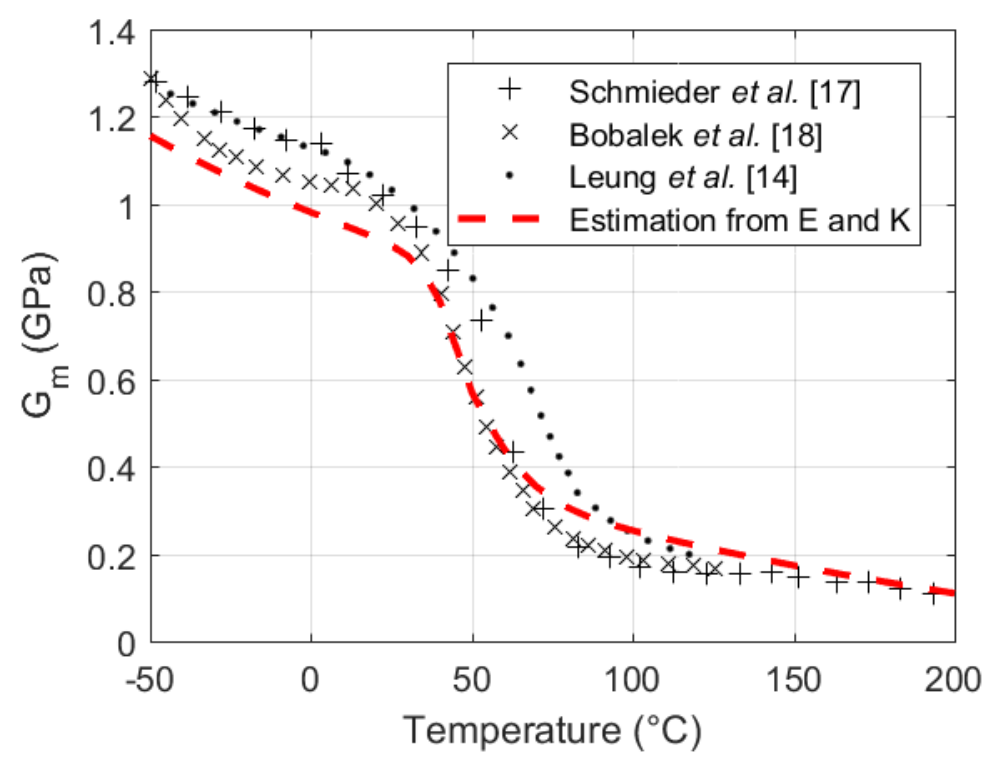

Figure 7. Evolution of the shear modulus of the PA66 matrix Gm as a function of the temperature and compared with several values from the literature [14,17,18]. 


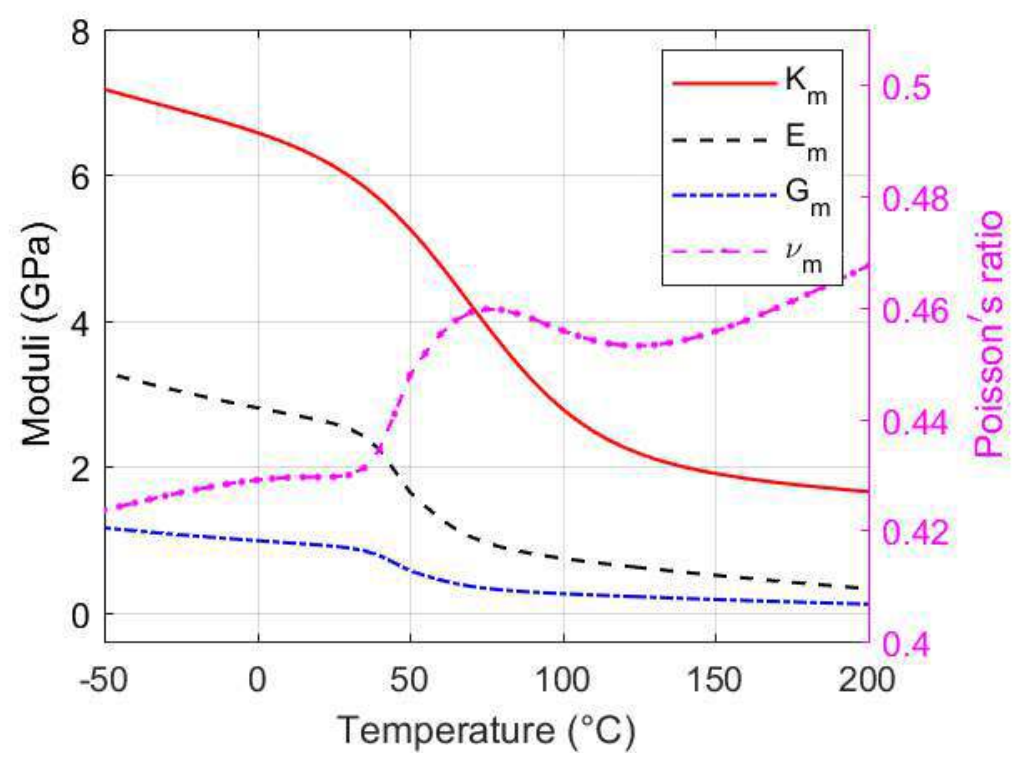

Figure 8. Evolution of the estimated PA66 Poisson's ratio vm as a function of temperature, together with its elastic moduli $\mathrm{Em}, \mathrm{Km}$ and $\mathrm{Gm}$.

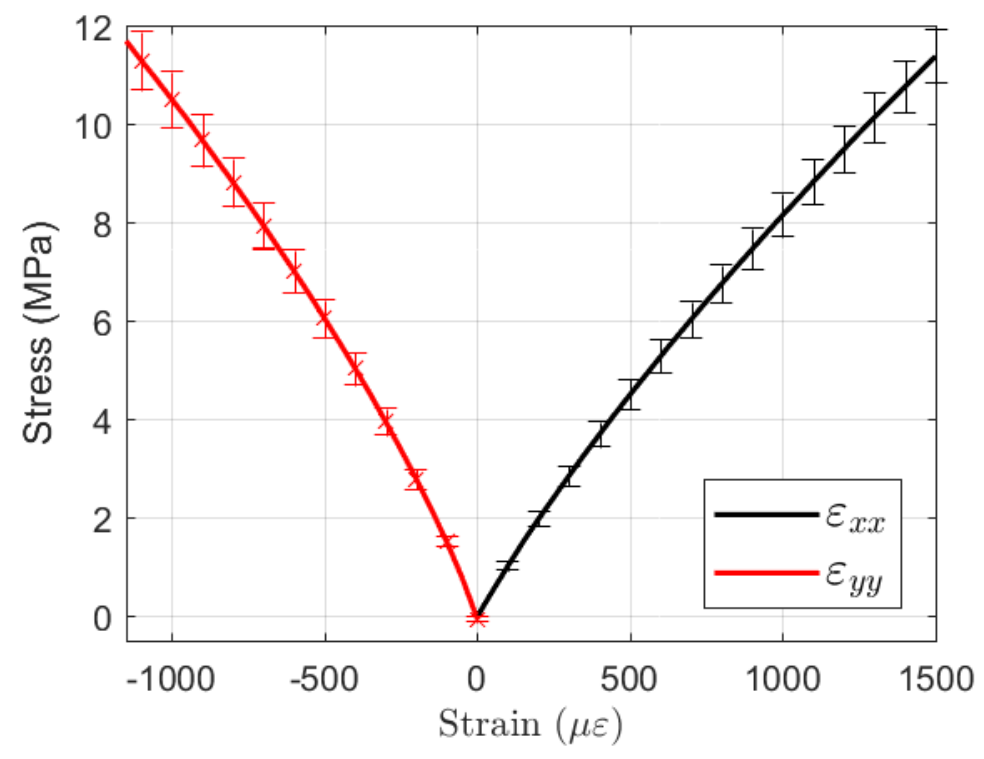

Figure 9. Evolution of the mean longitudinal and transversal strains for the $\left[+45_{2}-45_{2}\right]$ s ply sequence during tensile test. 
a)

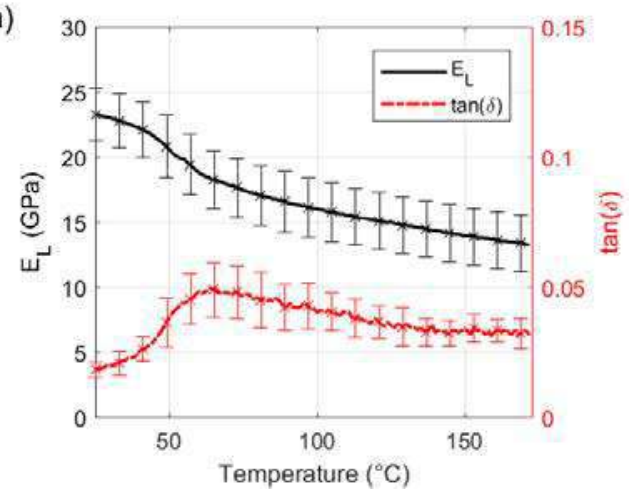

b)

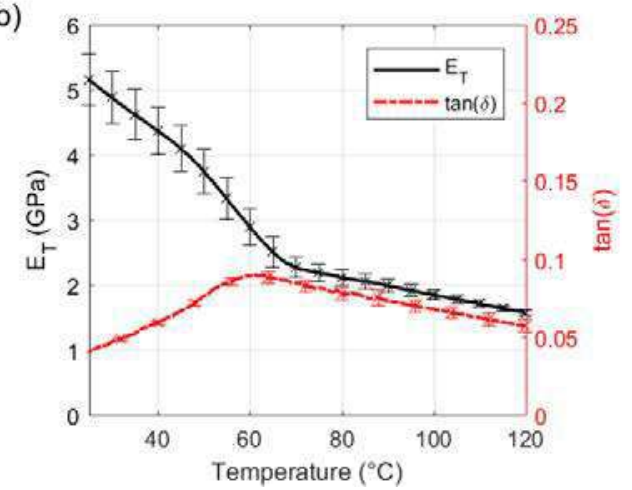

Figure 10. DMA results as a function of temperature for (a) the $\left[0^{\circ}\right]_{8}$ samples and (b) the $\left[90^{\circ}\right] 8$ samples.

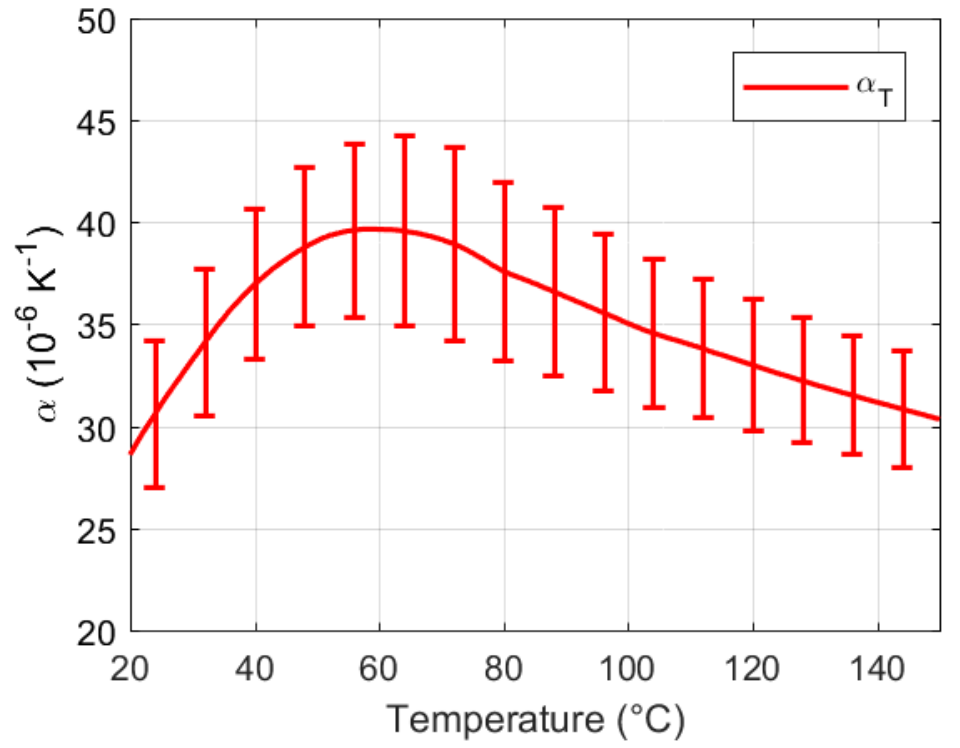

Figure 11. CTE measured in the transversal direction from the [90]8 samples.

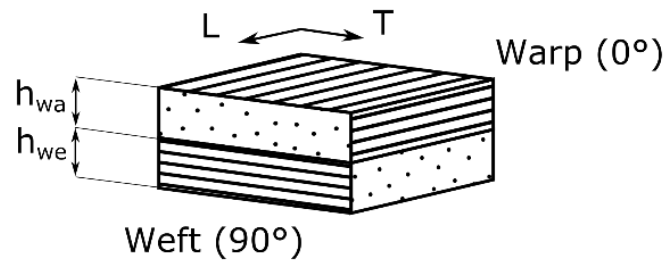

Figure 12. Simplification of the quasi-UD structure. 


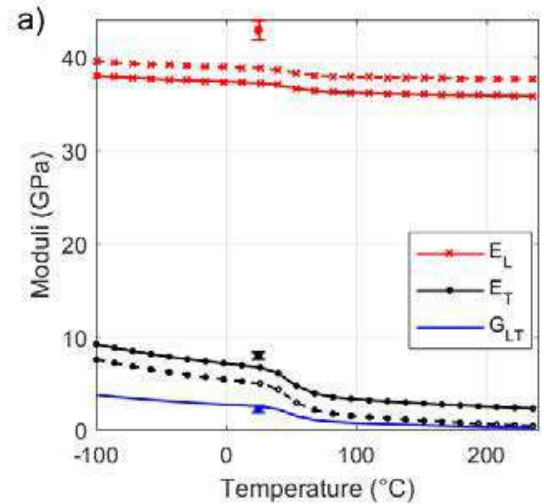

c)

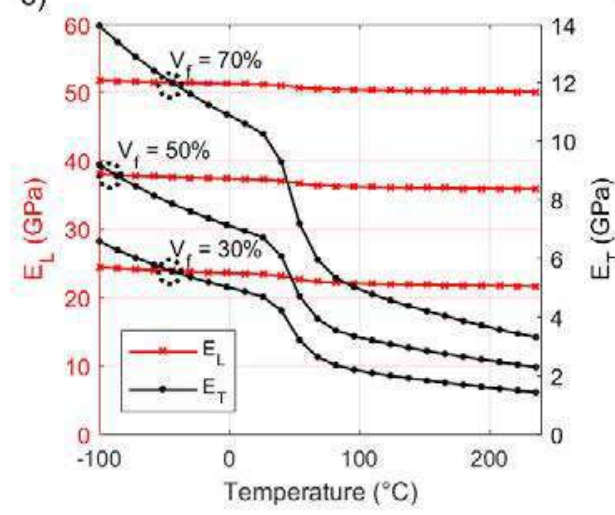

b)

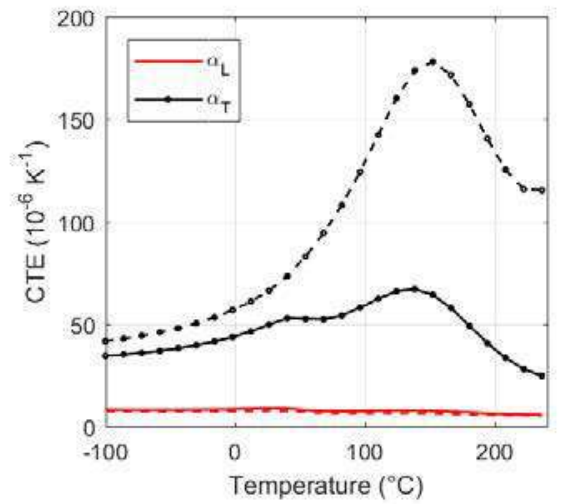

d)

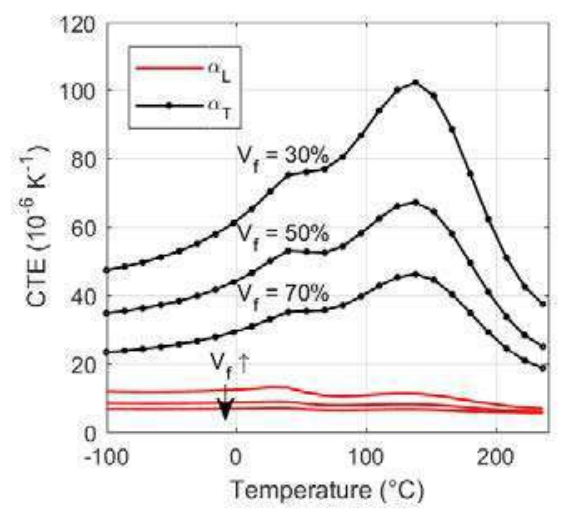

Figure 13. Evolution of the estimated composite properties with temperature. The UD properties are represented with dashed lines and the quasi-UD ones with continuous lines. (a) In-plane moduli for $\mathrm{V}_{\mathrm{f}}=50 \%$. (b) In-plane $\mathrm{CTE}$ for $\mathrm{V}_{\mathrm{f}}=50 \%$. (c) In-plane moduli for various $V_{f}$. (d) In-plane CTE for various $V_{f}$.

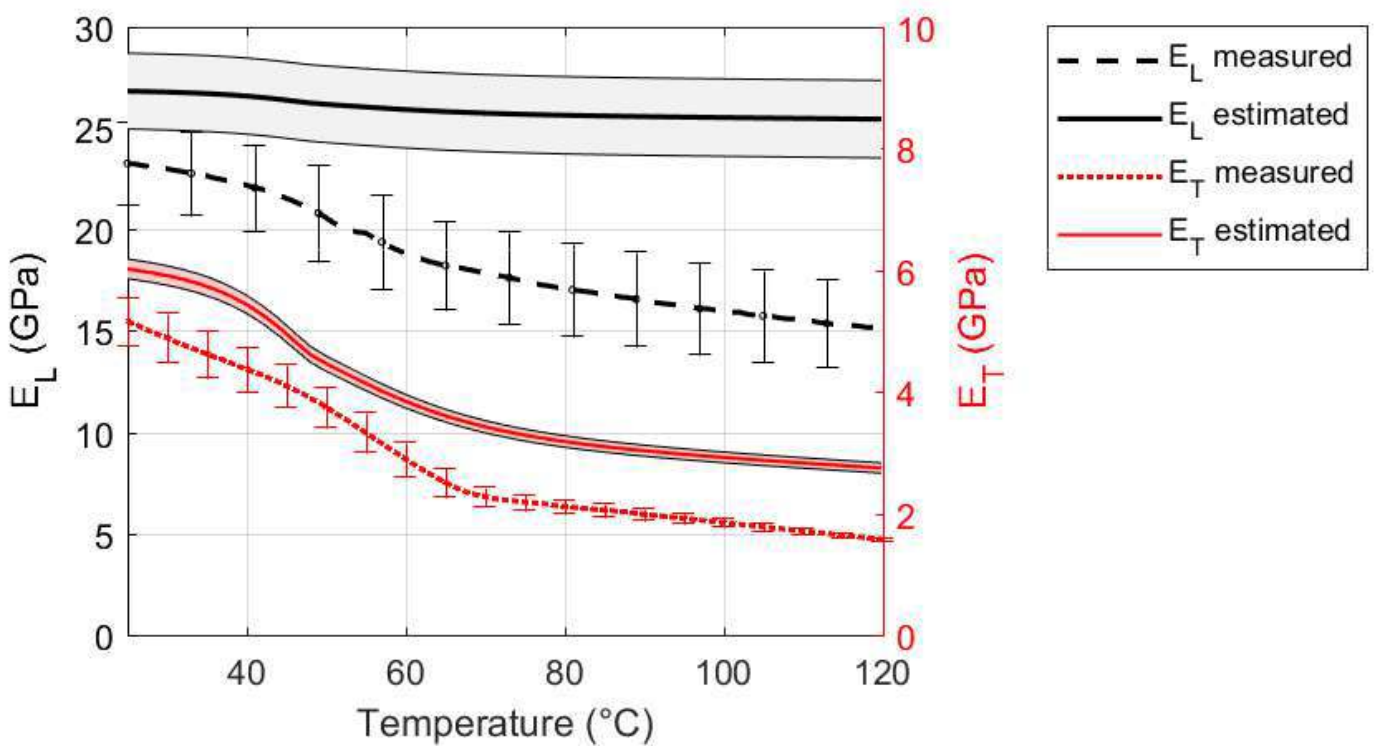


Figure 14. Evolution of the measured longitudinal and transversal Young's modulus together with the estimated ones. The filled area around the estimated properties correspond to the impact of the uncertainty of the fibre volume fraction.

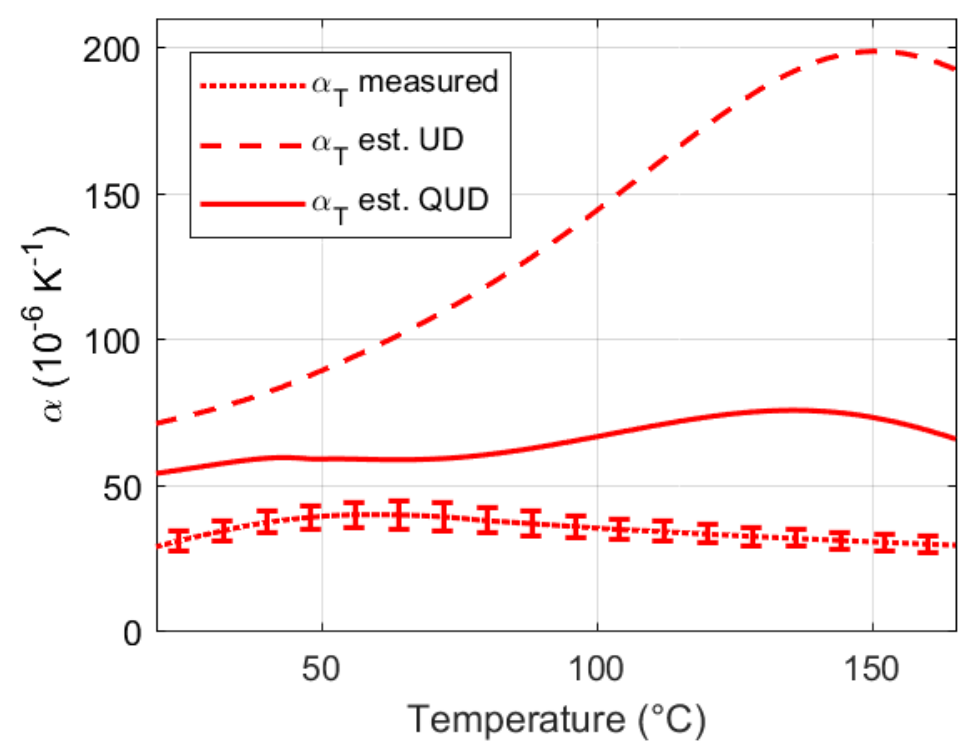

Figure 15. Comparison between the measured CTE and the estimated one through a UD and the QUD model. 